\title{
Pre-stimulation of CD81 expression by resting B cells increases proliferation following EBV infection, but the overexpression of CD81 induces the apoptosis of EBV-transformed B cells
}

\author{
GA BIN PARK $^{1 *}$, DAEJIN KIM ${ }^{1 *}$, SUNG JAE PARK $^{2}$, HYUN-KYUNG LEE ${ }^{2}$, \\ JI HYUN KIM ${ }^{2}$, YEONG SEOK KIM ${ }^{1}$, SAE-GWANG PARK ${ }^{3}$, IN-HAK CHOI ${ }^{3}$, SUNG HO YOON ${ }^{4}$, \\ YOUN JAE LEE ${ }^{2}$, SUNGHWA PAENG ${ }^{5}$ and DAE YOUNG HUR ${ }^{1}$ \\ ${ }^{1}$ Department of Anatomy and Research Center for Tumor Immunology, Inje University College of Medicine; \\ ${ }^{2}$ Department of Internal Medicine, Inje University Busan Paik Hospital; ${ }^{3}$ Department of Microbiology, \\ Inje University College of Medicine; ${ }^{4}$ Department of Plastic Surgery, Inje University Haeundae Paik Hospital; \\ ${ }^{5}$ Department of Neurosurgery, Inje University Busan Paik Hospital, Busan 614-735, Republic of Korea
}

Received January 11, 2015; Accepted September 23, 2015

DOI: $10.3892 /$ ijmm.2015.2372

\begin{abstract}
Hepatitis C virus (HCV) E2 protein binds to CD81, which is a component of the $\mathrm{B}$ cell co-stimulatory complex. The E2-CD81 interaction leads to B cell proliferation, protein tyrosine phosphorylation and to the hypermutation of immunoglobulin genes. Epidemiological studies have reported a high prevalence of B cell non-Hodgkin lymphoma (NHL) in HCV-positive patients, suggesting a potential association between HCV and Epstein-Barr virus (EBV) in the genesis of B lymphocyte proliferative disorders. In the present study, in order to investigate the association between EBV and HCV in $\mathrm{B}$ cells, we created an in vitro $\mathrm{EBV}$-induced B cell transformation model. CD81 was gradually overexpressed during transformation by EBV. B cells isolated from $\mathrm{HCV}$-positive patients grew more rapidly and clumped together earlier than B cells isolated from healthy donors following EBV infection. Pre-stimulation of CD81 expressed by resting B cells with anti-CD81 monoclonal antibody $(\mathrm{mAb})$ or HCV E2 accelerated the generation of lymphoblastoid cell lines (LCLs) by EBV infection. These cells proliferated prominently through the early expression of interleukin-10 and intracellular latent membrane protein (LMP)-1. By contrast, the overexpression of CD81 on EBV-transformed
\end{abstract}

Correspondence to: Professor Dae Young Hur, Department of Anatomy and Research Center for Tumor Immunology, Inje University College of Medicine, 75 Bokji-ro, Busanjin-gu, Busan 614-735, Republic of Korea

E-mail:dyhur@inje.ac.kr

Professor Sunghwa Paeng, Department of Neurosurgery, Inje University Busan Paik Hospital, 75 Bokji-ro, Busanjin-gu, Busan 614-735, Republic of Korea

E-mail: shpaeng@empal.com

${ }^{*}$ Contributed equally

Key words: hepatitis C virus, Epstein-Barr virus, CD81, apoptosis
B cells by anti-CD $81 \mathrm{mAb}$ or $\mathrm{HCV}$ E2 protein induced apoptosis through reactive oxygen species (ROS)-mediated mitochondrial dysfunction. These results suggest that the engagement of CD81 expressed by B cells has differential effects on B cell fate (proliferation or apoptosis) according to EBV infection and the expression level of CD81.

\section{Introduction}

CD81, also known as target of antiproliferative antibody 1 (TAPA-1), is a component of the B cell co-stimulatory complex. This complex consists of CD19, CD21 and interferon-inducible Leu-13 (CD225) (1). The simultaneous stimulation of this complex and the $\mathrm{B}$ cell receptor (BCR) by antigens magnifies signal transduction and increases B cell proliferation $(2,3)$. CD19 and CD21 are expressed exclusively on B cells, whereas CD81 and CD225 are widely expressed on immune cells (T, B and NK lymphocytes, monocytes and eosinophils), hepatocytes and on most stromal and epithelial cells (4). Genetic defects in CD81 disrupt CD19 complex formation and lead to antibody deficiency syndromes (5). CD19 expression and B cell activation by $\mathrm{T}$ cell-dependent antigens are also impaired in CD81-knockout mouse models $(6,7)$.

Hepatitis $\mathrm{C}$ virus (HCV) is a positive-stranded RNA Hepacivirus in the Flaviviridae family (8). HCV infection is associated with chronic liver diseases, such as chronic hepatitis, cirrhosis and hepatocellular carcinoma (HCC). HCV infection is also an important cause of autoimmune disease, type II mixed cryoglobulinemia (MC) and non-Hodgkin lymphoma (NHL) (9-11). Viral envelope proteins are composed of the heavily glycosylated envelope proteins, E1 and E2 (12). The large extracellular loop (LEL) of CD81 binds to the $\mathrm{E} 2$ dimer of $\mathrm{HCV}$ (13). The $\mathrm{E} 2$ glycoprotein of $\mathrm{HCV}$ is, therefore, the target of neutralizing antibodies as the $\mathrm{N}$-terminal ectodomain of $\mathrm{E} 2$ possesses the entry determinants for infection of the host cell (14). However, neutralizing antibodies against E2 are strain-specific and are modulated by a complex interplay between hypervariable regions (HVR)1 and 2 (15). 
Although certain epidemiological and experimental studies have suggested an etiopathogenetic role for HCV and EpsteinBarr virus (EBV) infection in B cell NHL pathogenesis, the distinct contribution of these two viruses to the progression of B cell NHL remains unclear and controversial $(16,17)$.

Lymphocytes from HCV-positive patients have been shown to express CD81 at significantly higher levels than lymphocytes from controls (18). CD81 has also been shown to play a role in the infection of primary human hepatocytes by serum-derived HCV (19). CD81 expression in B cells has been suggested to be involved in chronic antigenic stimulation related to $\mathrm{HCV}$ infection (20). B cells have been shown to be susceptible to $\mathrm{HCV}$, and direct $\mathrm{HCV}$ infection through CD81 on B cells has been proposed as a possible cause of NHL $(21,22)$. However, the binding of the E2 protein of $\mathrm{HCV}$ alone is insufficient to explain the function of CD81 expressed by mature B cells. CD81 engagement in B cells triggers the Raf/MEK/ERK signaling pathway that appears to be important for cell proliferation and survival (23). Furthermore, E2-CD81 engagement protects primary human B lymphocytes (PHB) from apoptosis through the phosphorylation of $\mathrm{I} \kappa \mathrm{B} \alpha$ and the increase in the expression of anti-apoptotic Bcl-2 family proteins (24).

Although previous studies have demonstrated the proliferative effects of the CD81-HCV E2 interaction on resting B cells, the role of this interatction in EBV infection and transformation remains unclear. The effects of CD81 overexpression on $\mathrm{B}$ cells also remain controversial. Previously, we reported that EBV has the unique ability to transform resting $\mathrm{B}$ cells into lymphoblastoid cell lines (LCLs) in vitro $(25,26)$. In the present study, we aimed to elucidate the effects of CD81 on resting and activated $\mathrm{B}$ cells. For this purpose, we upregulated the expression of CD81 in B cells by EBV infection and stimulated the cells with anti-CD81 monoclonal antibodies (mAbs) or HCV E2 protein, leading to a change in the effects of CD81 on $\mathrm{B}$ cells during the transformation process.

\section{Materials and methods}

Ethics statement. Informed consent for the present study was obtained from all participants and the study was approved by the Institutional Bioethics Review Board of the Medical College of Inje University, Busan, Korea (\#12-238).

Cells, antibodies and reagents. To establish EBV-transformed B cells, peripheral blood mononuclear cells (PBMCs) were obtained from the blood of 7 healthy human volunteers and 7 patients with chronic HCV by Ficoll-Paque density gradient centrifugation (GE Healthcare Biosciences, Pittsburgh, PA, USA). B cells were purified from the PBMCs using the MACS $B$ cell isolation kit and the MACS separator (both from Miltenyi Biotec, Bergisch Gladbach, Germany). Mouse anti-human CD81 mAb (5A6) for stimulation experiments was purchased from BD Biosciences (San Jose, CA, USA). FITC-conjugated anti-CD81 mAb (\#551108), PE-conjugated anti-CD20 antibody (\#346595), Fas (CD95) antibody (\#555674), Fas ligand (CD178) antibody (\#12-9919-42) and PE-conjugated anti-latent membrane protein (LMP)-1 antibody (\#550018) for FACS analysis were purchased from BD Biosciences. Recombinant purified HCV E2 protein was produced using the pCMVdhfrE2 plasmid (a gift from Dr Chang-Yuil Kang, Seoul National
University, Seoul, Korea) according to the protocol descrbied in the study by Heo et al (27). 2',7'-Dichlorofluorescin diacetate (DCFH-DA) and 3,3'-dihexyloxacarbocyanine iodide $\left(\mathrm{DiOC}_{6}\right.$ ) were purchased from Molecular Probes (Eugene, OR, USA). N-acetylcysteine (NAC), $N$-benzyloxycarbonyl-ValAla-Asp-fluoromethylketone (Z-VAD-fmk, $20 \mu \mathrm{M}$ in DMSO, a broad spectrum caspase inhibitor), $N$-benzyloxycarbonylAsp-Glu-Val-Asp-fluoromethylketone (Z-DEVD-fmk, $20 \mu \mathrm{M}$ in DMSO, a caspase-3 inhibitor), and $N$-benzyloxycarbonylIle-Glu-Thr-Asp-fluoromethylketone (Z-IETD-fmk, $20 \mu \mathrm{M}$ in DMSO, a caspase-8 inhibitor) were purchased from Calbiochem (San Diego, CA, USA).

Generation of EBV-transformed B cells and analysis of phenotype. EBV stock was prepared from an EBV-transformed B95-8 marmoset cell line (a gift from Dr B.G. Han, National Genome Research Institute, National Institute of Health, Seoul, Korea). To establish an EBV-infected B cell line from the PBMCs, $10 \mathrm{ml}$ of peripheral blood were collected from 7 healthy human donors and 7 patients with chronic HCV. The characteristics of the patients with HCV are presented in Table I. Qualitative and quantitative PCR analyses for HCV RNA were evaluated with Amplicor HCV version 2.0 (Roche Molecular System, Pleasanton, CA, USA). HCV genotypes were determined by reverse hybridization (INNO-LiPA, Innogenetics, Ghent, Belgium). The B cells were purified from the PBMCs using the MACS B cell isolation kit and a MACS separator (Miltenyi Biotec). The purified B cells were added to EBV stock supernatant in a culture flask, and following $2 \mathrm{~h}$ of incubation at $37^{\circ} \mathrm{C}$, an equal volume of RPMI-1640 medium (HyClone, Logan, UT, USA) containing 10\% fetal bovine serum (HyClone) and $1 \mu \mathrm{g} / \mathrm{ml}$ of cyclosporine A (Sigma-Aldrich, St. Louis, MO, USA) were added $\left(1 \times 10^{6}\right.$ cells $\left./ \mathrm{ml}\right)$. The cultures were incubated for 2-4 weeks until clumps of EBV-infected $B$ cells were visible and the medium had turned yellow, as previously descrbied $(25,26)$. The phenotype of EBV-transformed $\mathrm{B}$ cells was monitored each week by flow cytometric analysis and a confocal laser-scanning microscope (510 META; Carl Zeiss, Oberkochen, Germany) at x400 original magnification using FITC-conjugated anti-CD81 and PE-conjugated antiCD20 mAbs (BD Biosciences).

Monitoring the changes in the morphology of $E B V$-transformed $B$ cells pre-stimulated with CD81. For CD81 pre-stimulation with antibody, the purified resting $B$ cells were suspended in $100 \mu \mathrm{l}$ PBS and incubated with antiCD81 mAb (BD Biosciences; 5A6, $10 \mu \mathrm{g} / \mathrm{ml}$ ) or an isotype control antibody (MOPC21; IgG1 $; 10 \mu \mathrm{g} / \mathrm{ml}$; Sigma-Aldrich) at $37^{\circ} \mathrm{C}$ for $30 \mathrm{~min}$. The incubated cells were washed in PBS and resuspended in $100 \mu \mathrm{l}$ PBS and then incubated with goat anti-mouse IgG (2 $\mu \mathrm{g} / \mathrm{ml}$; Sigma-Aldrich) for $15 \mathrm{~min}$ at $37^{\circ} \mathrm{C}$. The purified resting B cells were also cultured in RPMI-1640 medium supplemented with HCV E2 protein $(2 \mu \mathrm{g} / \mathrm{ml})$ or serum obtained from patients with HCV (diluted 1/20). CD81-prestimulated B cells were added to EBV stock supernatant in a culture flask, followed by $2 \mathrm{~h}$ of incubation at $37^{\circ} \mathrm{C}$. We then generated EBV-transformed B cells as described above. Cell aggregation and clumping of the B cells following EBV infection were measured at the indicated time points (days 2 and 4, and weeks 1,2, 3 and 4) under a microscope. 
Table I. Characteristics of patients with chronic HCV.

\begin{tabular}{lccccccc}
\hline Characteristic & $\mathrm{A}$ & $\mathrm{B}$ & $\mathrm{C}$ & $\mathrm{D}$ & $\mathrm{E}$ & $\mathrm{F}$ & $\mathrm{G}$ \\
\hline Gender/age (years) & $\mathrm{M} / 25$ & $\mathrm{M} / 58$ & $\mathrm{~F} / 42$ & $\mathrm{M} / 54$ & $\mathrm{~F} / 45$ & $\mathrm{M} / 38$ & $\mathrm{M} / 50$ \\
ALT (U/l) & 77 & 62 & 73 & 64 & 91 & 99 & 47 \\
PCR for HCV & Positive & Positive & Positive & Positive & Positive & Positive & Positive \\
Genotype & $1 \mathrm{~b}$ & $1 \mathrm{~b}$ & $1 \mathrm{~b}$ & $1 \mathrm{~b}$ & $1 \mathrm{~b}$ & $2 \mathrm{a} / 2 \mathrm{c}$ & $2 \mathrm{~b}$ \\
HCV RNA (x106 IU/ml) & 4.2 & 4.4 & 2.6 & 2.6 & 1.7 & 1.3 & 3.6 \\
Biopsy results & $\mathrm{F} 0$ & $\mathrm{~F} 3$ & $\mathrm{~F} 2$ & $\mathrm{~F} 3$ & Not checked & Not checked & Not checked \\
Sampling date & 01.10 .04 & 21.12 .04 & 04.02 .04 & 16.03 .05 & 04.07 .05 & 09.08 .05 & 02.09 .05 \\
Date of antiviral treatment & 28.03 .05 & 05.01 .05 & 14.03 .05 & 25.03 .05 & - & 02.09 .05 & 02.09 .05 \\
Type of response & SVR & SVR & SVR & relapse & Not treated & Follow-up loss & SVR \\
\hline
\end{tabular}

No patients had a prior history of interferon treatment for chronic hepatitis C. Detection limit of qualitative PCR analysis is $50 \mathrm{IU} / \mathrm{ml}$. Dynamic range of quantitative PCR analysis is $600-500,000 \mathrm{IU} / \mathrm{ml}$. Biopsy results are tabulated on the Metavir scoring system for fibrosis staging. All dates are presented in the format of day/month/year. ALT, alanine aminotransferase; IU, international units; F0, portal inflammation without fibrosis; F2, portal fibrosis with rare septa; F3, numerous septa without cirrhosis; SVR, sustained viral response; M, male; F, female.

Measurement of the proliferation of EBV-transformed $B$ cells. B cells from healthy donors or patients with HCV were stimulated with anti-CD81 antibody $(10 \mu \mathrm{g} / \mathrm{ml})$ or HCV E2 protein $(2 \mu \mathrm{g} /$ $\mathrm{ml})$ prior to EBV infection. At 2 weeks after EBV infection, the EBV-transformed B cells from healthy donors or patients with HCV $\left(2 \times 10^{4}\right.$ cells/well) were harvested and cultured in RPMI1640 medium containing 10\% FBS in 96-well flat bottom plates. After $48 \mathrm{~h}$, cell proliferation was measured using the alamarBlue assay (AbD Serotec, Raleigh, NC, USA). The alamarBlue reagent was added ( $10 \%$ by volume) to each well and relative fluorescence was determined $7 \mathrm{~h}$ later using a fluorometer (Synergy HT; Bio-Tek Instruments, Inc., Winooski, VT, USA; excitation, $530 \mathrm{~nm}$; emission, $590 \mathrm{~nm}$ ). The purified naïve B cells and B cells stimulated with anti-CD81 mAb were also cultured under the same conditions as the controls (untreated cells). All experiments were performed in triplicate, and the relative fluorescence number used was the mean fluorescence determined for each culture. Data are expressed as the means \pm standard deviation (SD) and analyzed using the Student's t-test. A p-value $<0.05$ was considered to indicate a statistically significant difference.

Detection of EBV-induced protein and interleukin (IL)-10 $m R N A$ and protein expression. To measure the intracellular expression levels of LMP-1, LMP-2A, Epstein-Barr virus nuclear antigen (EBNA)-1, EBNA-2, EBNA-3A and IL-10 in $B$ cells during EBV transformation, the cells and culture media were harvested each week to measure the LMP-1 and IL-10 expression levels for 4 weeks. The cells were then permeabilized with permeabilization buffer $(0.1 \%$ saponin; Sigma-Aldrich, in PBS) for $5 \mathrm{~min}$. The cells were washed twice in PBS following centrifugation ( $400 \mathrm{x} \mathrm{g}$, at $4^{\circ} \mathrm{C}$ for $5 \mathrm{~min}$ ), and cell pellets were stained with PE-conjugated anti-LMP-1 or IL-10 antibodies for $30 \mathrm{~min}$ at $4^{\circ} \mathrm{C}$. Following 3 washes, the cells were fixed in $4 \%$ paraformaldehyde solution (Sigma-Aldrich) for $10 \mathrm{~min}$. Expression levels were determined using a FACSCalibur flow cytometer (BD Biosciences). To detect EBV proteins by western blot analysis, B cells were harvested at 2 and 4 weeks following transformation with EBV. The cells $\left(2 \times 10^{6}\right.$ cells/sample) were pelleted and lysed in RIPA buffer (Elpis-Biotech, Inc., Daejeon, Korea). Proteins (20 $\mu \mathrm{g} / \mathrm{sample})$ were immediately heated for
5 min at $100^{\circ} \mathrm{C}$. Total cell lysates were subjected to SDS-PAGE on gels containing $15 \%$ (wt/vol) acrylamide under reducing conditions. Anti-LMP-1 antibody for western blot analysis was purchased from Abnova (Taipei, Taiwan). Anti-EBNA-1 antibody was purchased from Thermo Fisher Scientific, Inc., (Pittsburg, PA, USA). Anti-EBNA-2 and anti-LMP-2A antibodies were purchased from Santa Cruz Biotechnology, Inc., (Santa Cruz, CA, USA). To measure the mRNA and protein expression levels of IL-10, B cells isolated from healthy donors were stimulated with anti-CD81 mAb prior to EBV infection. Mouse anti-human CD19 mAb (BD Biosciences) was used as a positive control. The EBV-transformed B cells were harvested each week to determine the intracellular IL-10 levels. Total RNA from the EBV-transformed B cells was isolated at the indicated time points using an RNeasy Mini kit (Qiagen, Hilden, Germany). The RNA was reverse transcribed into cDNA using oligo(dT) primers (Bioneer Corp., Daejeon, Korea) and reverse transcriptase. PCR amplification was performed using specific primer sets (Bioneer Corp.) for human IL-10 (upstream primer, 5'-CTG AGA ACC AAG ACC CAG ACA TCA AGG and downstream primer, 5'-GTC AGC TAT CCC AGA GCC CCA GAT CCG; 327-bp product). As a control, a primer set specific for $\beta$-actin (upstream primer, 5'-ATC CAC GAA ACT ACC TTC AA and downstream primer, 5'-ATC CAC ACG GAG TAC TTG C) was used. PCR ( 25 cycles; $20 \mathrm{sec}$ at $94^{\circ} \mathrm{C}, 10 \mathrm{sec}$ at $60^{\circ} \mathrm{C}, 30 \mathrm{secs}$ at $72^{\circ} \mathrm{C}$ ) was performed using AccuPower PCR PreMix (Bioneer Corp.). PCR products were analyzed by agarose gel electrophoresis and visualized with ethidium bromide under UV light using the Multiple Gel DOC system (Fujifilm, Tokyo, Japan). Densitometry was performed using Multi Gauge version 2.3 software (Fujifilm). The culture supernatant from EBV-transformed B cells stimulated with antiCD81 mAb or serum derived from $\mathrm{HCV}$ patients (diluted 1/20) was harvested at 1, 2 and 4 weeks to detect IL-10 level. IL-10 protein was detected and quantified using the Single-Analyte ELISArray kit (Qiagen, Hilden, Germany). MOPC, the isotype control, and healthy donor serum were used as controls.

Induction and detection of CD81-mediated apoptosis. Four weeks following infection, the EBV-transformed 
B cells $\left(1 \times 10^{6}\right.$ cells $\left./ \mathrm{ml}\right)$ were harvested and washed twice in cold PBS. The cells were resuspended in $100 \mu 1$ PBS and incubated with anti-CD81 mAb $(10 \mu \mathrm{g} / \mathrm{ml}$; BD Biosciences $)$ or the isotype control antibody (MOPC, Sigma-Aldrich, $10 \mu \mathrm{g} / \mathrm{ml}$ ) at $37^{\circ} \mathrm{C}$ for $30 \mathrm{~min}$. The cells were washed in PBS and resuspended in $100 \mu \mathrm{l}$ PBS and then incubated with goat anti-mouse IgG (Sigma-Aldrich; $2 \mu \mathrm{g} / \mathrm{ml}$ ) for $15 \mathrm{~min}$ at $37^{\circ} \mathrm{C}$. Following stimulation with antibody, the cells were washed and then cultured in RPMI-1640 medium at $37^{\circ} \mathrm{C}$. For stimulation with recombinant $\mathrm{HCV}$ E2 protein, the EBV-transformed B cells (4 weeks following infection, $1 \times 10^{6}$ cells $/ \mathrm{ml}$ ) were resuspended in $100 \mu \mathrm{l}$ PBS and incubated with $\mathrm{HCV}$ E2 protein $(1 \mu \mathrm{g} / \mathrm{ml})$ at $37^{\circ} \mathrm{C}$ for $1 \mathrm{~h}$. Following incubation, the cells were harvested and washed twice with PBS and resuspended in $100 \mu 1$ of $1 \mathrm{X}$ binding buffer (10 mM HEPES/NaOH, pH 7.4; 140 mM NaCl; 2.5 mM CaCl $)$. Apoptosis was then determined using an FITC Apoptosis Detection kit (BD Biosciences) according to the manufacturer's instructions. To detect the subG1 peak, the cells were harvested following treatment, washed twice in PBS (2\% FBS), fixed with $70 \%$ cold aqueous ethanol, and stored at $4^{\circ} \mathrm{C}$ for at least $24 \mathrm{~h}$. The cells were washed twice in PBS following centrifugation $\left(400 \mathrm{x} \mathrm{g}\right.$, at $4^{\circ} \mathrm{C}$ for $\left.5 \mathrm{~min}\right)$, and cell pellets were stained with propidium iodide (PI; Sigma-Aldrich) staining solution containing RNase A $(10 \mu \mathrm{g} / \mathrm{ml})$ and PI $(10 \mu \mathrm{g} / \mathrm{ml})$ in PBS. The cell suspension was then incubated in the dark at room temperature for $30 \mathrm{~min}$, and the DNA content was determined using a FACSCalibur flow cytometer (BD Biosciences).

Measurement of mitochondrial membrane potential $(\Delta \psi \mathrm{\psi m})$ and reactive oxygen species (ROS) levels. To determine whether CD81-induced apoptosis is related to the disruption of $\Delta \psi \mathrm{m}$ and ROS production, we measured the $\Delta \psi \mathrm{m}$ and ROS levels in the EBV-transformed B cells following CD81 cross-linking. The EBV-transformed B cells $\left(1 \times 10^{6}\right.$ cells/well) were pre-treated with $10 \mu \mathrm{M}$ DCFH-DA for $30 \mathrm{~min}$ to measure the ROS levels. To measure $\Delta \psi \mathrm{m}$, the cells were collected and pre-incubated in $100 \mu \mathrm{l} \mathrm{PBS}$ containing $20 \mu \mathrm{M} \mathrm{DiOC}_{6}$ at $37^{\circ} \mathrm{C}$ for $15 \mathrm{~min}$, and the cells were then washed twice with cold PBS and treated with mouse-anti-human CD81 mAb or HCV E2 protein for $3 \mathrm{~h}$ at $37^{\circ} \mathrm{C}$. The cells were then harvested at various time points $(0,10,20,30 \mathrm{~min}, 1,2$ and $3 \mathrm{~h})$ and washed 3 times with cold PBS. The ROS levels and $\Delta \psi \mathrm{m}$ were determined using a FACSCalibur flow cytometry (BD Biosciences). To determine whether CD81-induced apoptosis is related to mitochondrial dysfunction, the EBV-transformed B cells $\left(1 \times 10^{6}\right.$ cells $\left./ \mathrm{ml}\right)$ were pre-incubated for $30 \mathrm{~min}$ with $300 \mu \mathrm{M}$ antimycin A (Sigma-Aldrich), a mitochondrial complex III inhibitor. The cells were then washed with PBS and treated with mouse anti-human CD81 mAb $(10 \mu \mathrm{g} / \mathrm{ml})$ or MOPC $(10 \mu \mathrm{g} / \mathrm{ml})$ for $1 \mathrm{~h}$ at $37^{\circ} \mathrm{C}$. The cells were then washed twice with PBS and incubated for $1 \mathrm{~h}\left(5 \times 10^{5}\right.$ cells/well). The apoptotic rate, ROS production and $\Delta \psi \mathrm{m}$ were analyzed using a FACSCalibur flow cytometer (BD Biosciences).

Inhibition of apoptosis. To investigate the effects of caspase inhibitors and ROS, the EBV-transformed B cells were treated with Z-VAD-fmk, Z-IETD-fmk, Z-DEVD-fmk (20 $\mu \mathrm{M}$ in DMSO; Calbiochem), or NAC for $2 \mathrm{~h}$ prior to stimulation with the antibodies. The cells were incubated with anti-CD81 mAb (10 g/ml; BD Biosciences $)$ at $37^{\circ} \mathrm{C}$ for
$40 \mathrm{~min}$ followed by cross-linking with goat anti-mouse $\mathrm{IgG}$ (2 $\mu \mathrm{g} / \mathrm{ml}$; Sigma-Aldrich) for $15 \mathrm{~min}$ at $37^{\circ} \mathrm{C}$. The inhibitory effects of caspase inhibitors or NAC on the apoptosis of EBV-transformed B cells were detected by Annexin V, DCFH-DA and DiOC $_{6}$ staining as described above. To block the Fas-FasL interaction, antagonistic anti-Fas antibody (ZB4; Abcam, Cambridge, MA, USA, $0.5 \mu \mathrm{g} / \mathrm{ml}$ ) was added $1 \mathrm{~h}$ prior to treatment with anti-CD81 mAb. ZB4 was removed from the cell cultures prior to stimulation with anti-CD81 $\mathrm{mAb}$. Apoptosis was determined by flow cytometry following staining with Annexin V (BD Biosciences).

Confocal microscopy to detect apoptosis-related intracellular molecules. The EBV-transformed B cells were first cross-linked with anti-CD81 mAb and then secondary antibodies to induce apoptosis. To detect intracellular apoptosis-related molecules, teh cells were permeabilized with permeabilization buffer (0.1\% saponin in PBS). The cells were incubated with primary antibodies against cytochrome $c$ (mouse IgG2b; Santa Cruz Biotechnology, Inc., Dallas, TX, USA), apoptosis-inducing factor (AIF; mouse IgG2b; Santa Cruz Biotechnology, Inc.) and then FITC-conjugated goat anti-mouse IgG (Sigma-Aldrich) for $30 \mathrm{~min}$. Nuclei were stained with PI for $10 \mathrm{~min}$ at room temperature. Following 3 washes with PBS, the cells were mounted on microscopic slides under coverslips using fluorescence mounting medium (DakoCytomation, Glostrup, Denmark). Fluorescence-stained cells were examined under a confocal laser-scanning microscope (510 META; Carl Zeiss) at $\mathrm{x} 400$ original magnification and images were acquired using confocal microscopy software release 3.0 (Carl Zeiss).

Western blot analysis of apoptosis-related proteins. Following stimulation as described above, the EBV-transformed B cells were pelleted and lysed in RIPA buffer (Elpis-Biotech, Inc.). Proteins (10 $\mu \mathrm{g} / \mathrm{sample})$ were immediately heated for $5 \mathrm{~min}$ at $100^{\circ} \mathrm{C}$. Total cell lysates $\left(5 \times 10^{6}\right.$ cells/sample) were subjected to SDS-PAGE on gels containing $15 \%$ (wt/vol) acrylamide (Sigma-Aldrich) under reducing conditions. Separated proteins were transferred onto nitrocellulose membranes (Millipore, Billerica, MA, USA), and membranes were blocked with $5 \%$ skim milk followed by commercial western blot analysis. Chemiluminescence was detected using an ECL kit (Amersham Biosciences, Pittsburgh, PA, USA) and the Multiple Gel DOC system (Fujifilm). The following primary antibodies were used: caspase-8, caspase-3, caspase-9, $\beta$-actin, phosphorylated (p-)ERK1/2, ERK1/2, p-Akt (Ser473), Akt, p-JNK (Thr183/Tyr185), JNK and poly(ADP-ribose) polymerase (PARP) from Cell Signaling Technology, Inc., (Danvers, MA, USA) and p-c-Jun and c-Jun from Santa Cruz Biotechnology, Inc.

RT-PCR to detect apoptosis and anti-apoptosis-related molecules. Following stimulation as described above, total RNA was isolated using the RNeasy Mini kit (Qiagen). RNA was reverse transcribed into cDNA using oligo(dT) primers (Bioneer Corp.) and reverse transcriptase. PCR amplification was performed using specific primer sets (Bioneer Corp.) for Bcl-2 (upstream primer, 5'-GGA TTG TGG CCT TCT TTG AG-3' and downstream primer, 5'-CAG CCA GGA GAA ATC AAA CAG-3'; 209-bp product), Bax (upstream primer, 5'-CCA AGA AGC 
A

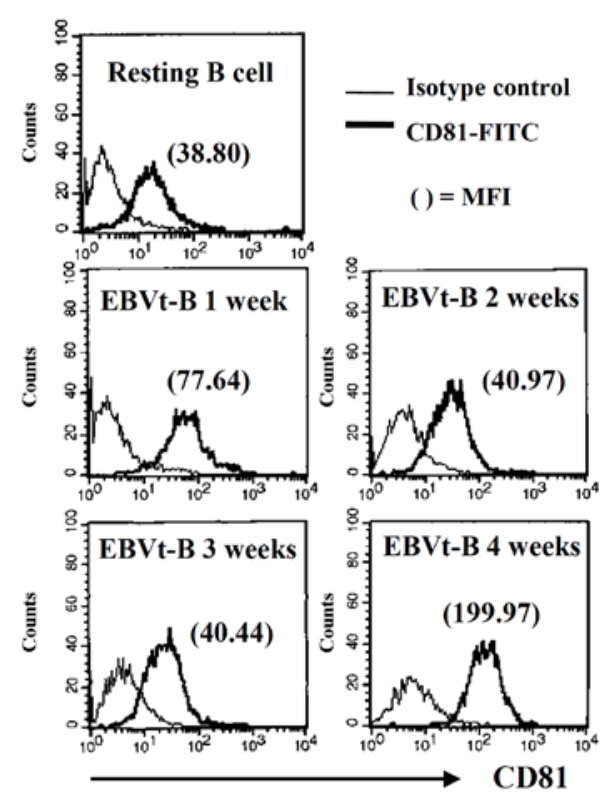

B

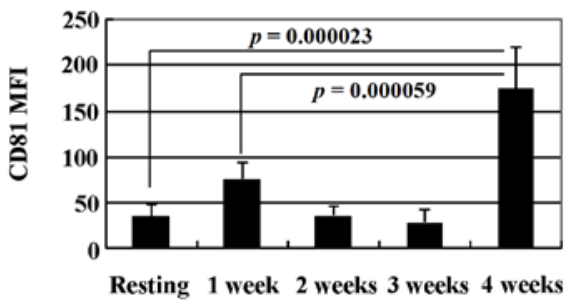

C
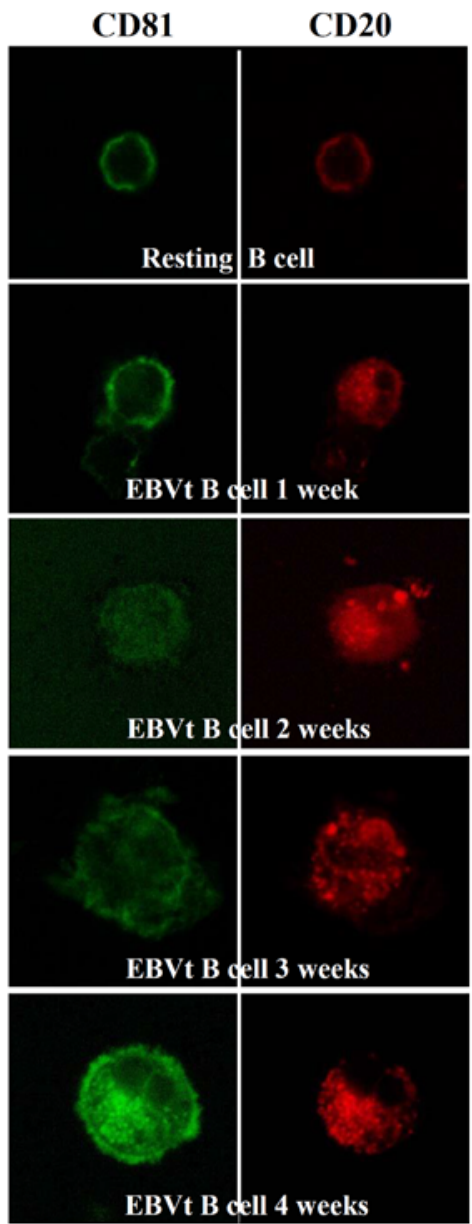

Figure 1. Changes in CD81 expression by B cells during Epstein-Barr virus (EBV) transformation (EBVt). Purified B cells were transformed with prepared EBV infectious supernatant. CD81 expression was assessed during the immortalization process by flow cytometry and confocal microscopy as described in the Materials and methods. (A) Cells taken each week following EBV infection were stained with FITC-conjugated anti-CD81 antibodies. The indicated numbers represent the proportion of positive cells. Thin-line histograms represent staining with isotype-control antibody (MOPC21), and thick-line histograms depict the expression of CD81 molecules. (B) Mean fluorescence intensity (MFI) calculated by flow cytometry. Graph shows the mean fluorescence intensities for CD81positive cells at 0-4 weeks following EBV infection. Data are shown as the means \pm SEM of triplicates. Comparisons between all individual data were made using one-way ANOVA. (C) Cells were collected and stained with FITC-conjugated anti-CD81 antibodies and PE-conjugated anti-CD20 antibodies at 0 , 1, 2, 3 and 4 weeks following EBV infection, and then fixed and examined by confocal microscopy. Confocal microscopic images show the expression of CD81 (green color) and CD20 (red color) (original magnification, $\mathrm{x} 400$ ). This figure is representative of 4 independent experiments.

TGA GCG AGT GT-3' and downstream primer, 5'-CAG CCC ATG ATG GTT CTG AT-3'; 250-bp product), and Bad (upstream primer, 5'-CGA GTG AGC AGG AAG ACT CC-3' and downstream primer, 5'-CTG TGC TGC CCA GAG CTT-3'; 299-bp product). As a control, a specific primer set for $\beta$-actin (upstream primer, 5'-ATC CAC GAA ACT ACC TTC AA-3, downstream primer, 5'-ATC CAC ACG GAG TAC TTG C-3') was used. PCR ( 25 cycles; $20 \mathrm{sec}$ at $94^{\circ} \mathrm{C}, 10 \mathrm{sec}$ at $60^{\circ} \mathrm{C}, 30 \mathrm{sec}$ at $72^{\circ} \mathrm{C}$ ) was performed using AccuPower PCR PreMix (Bioneer Corp.). PCR products were analyzed as described above.

Statistical analysis. The cell proliferation or mean fluorescence intensity (MFI) data are expressed as the means \pm standard error of the mean (SEM) from representative experiments. All data shown were confirmed by at least 3 independent experiments and are representative of at least 3 different experiments. The data were compared by one-way analysis of variance (ANOVA) using SPSS software for Windows, version 20.0 (SPSS Inc., Chicago, IL, USA). A p-value $<0.05$ was considered to indicate a statistically significant difference.

\section{Results}

EBV infection enhances $C D 81$ expression in resting $B$ cells. CD81 (TAPA-1) is expressed on the surface of most cells in the body, including B cells throughout their cellular differentiation (1). Resting B lymphocytes from peripheral blood were harvested to evaluate the changes in CD81 expression by flow cytometry and confocal microscopy each week for 4 weeks following EBV infection. The expression of CD81 was slightly increased at 1 week following infection; however, the expression of CD81 was not altered in the second and third weeks compared with resting B cells. Of note, the MFI of CD81 in EBV-transformed B cells was increased by approximately 5-fold compared to the resting B cells at 4 weeks following EBV infection (Fig. 1A and B). These changes in the expression pattern of CD81 in the EBV-infected B cells during the transformation process was also detected by confocal microscopy (Fig. 1C). These results suggest that the expression of CD81, which is expressed constitutively on mature B cells, may be increased during the late stages of EBV transformation. 
$\mathbf{A}$

Healthy donor

B cells + EBV

HCV patient

B cells $+\mathbf{E B V}$

B

Healthy donor B cells

+ Isotype Ab

$+\mathbf{E B V}$

Healthy donor B cells

+ anti-CD81

+ EBV

C

Healthy donor B cells + control cell extract + EBV

Healthy donor B cells + HCV E2 protein + EBV

D

Healthy donor B cells + donor serum

+ EBV $+\mathrm{HCV}$ patients' serum + EBV
Healthy donor B cells
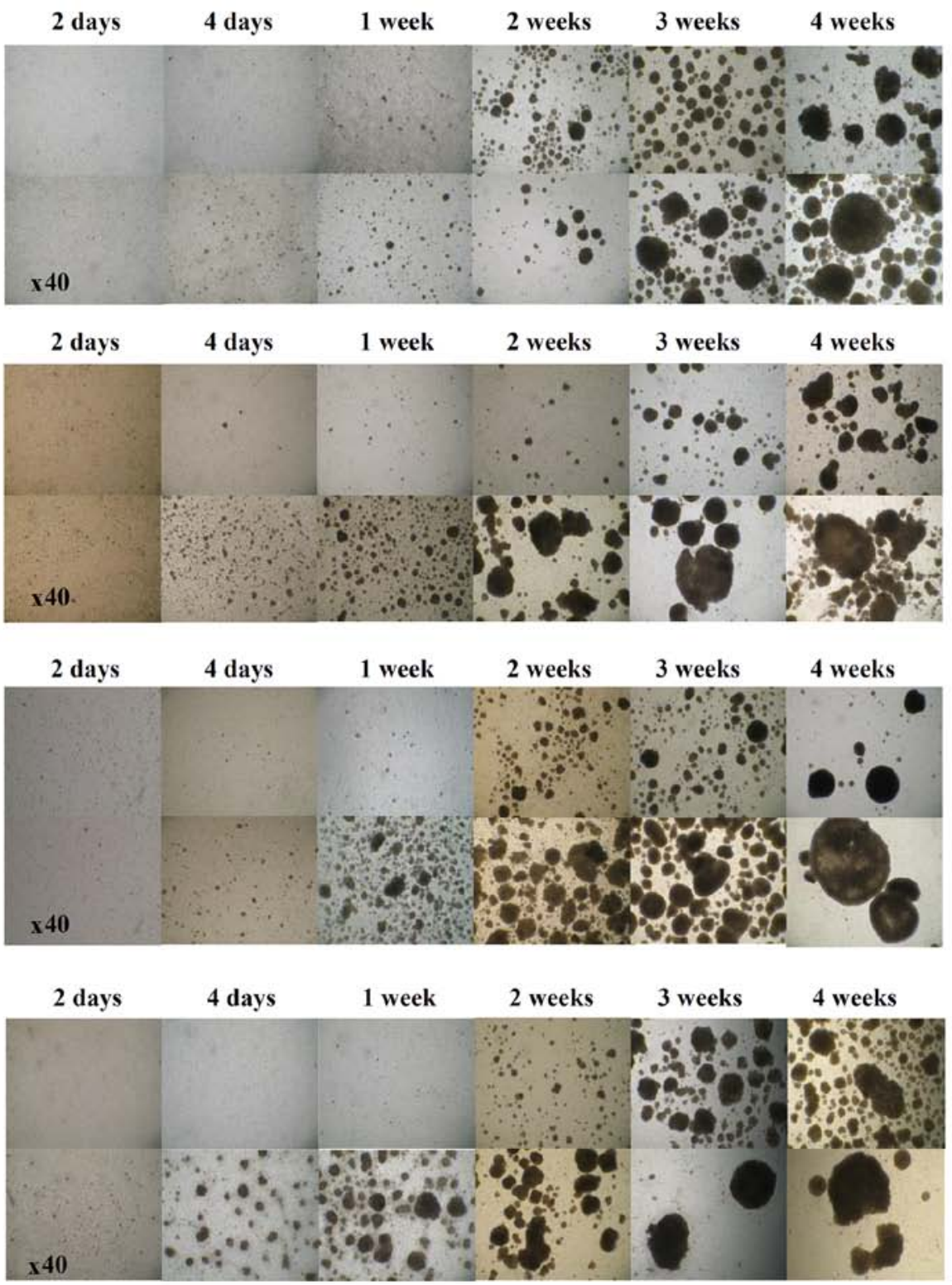

E

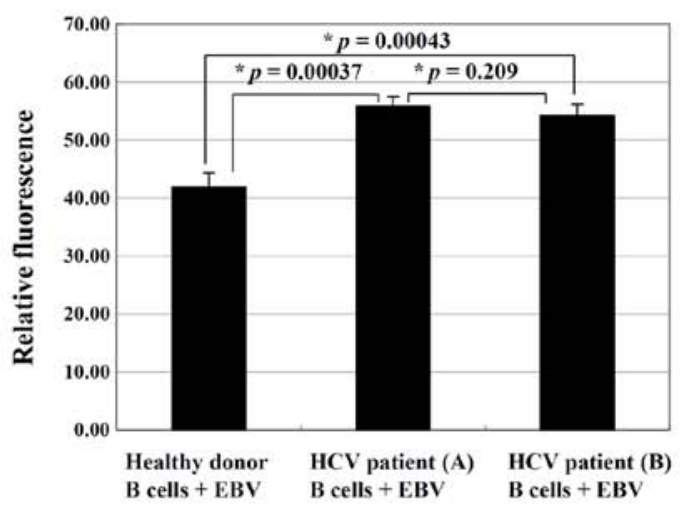

F

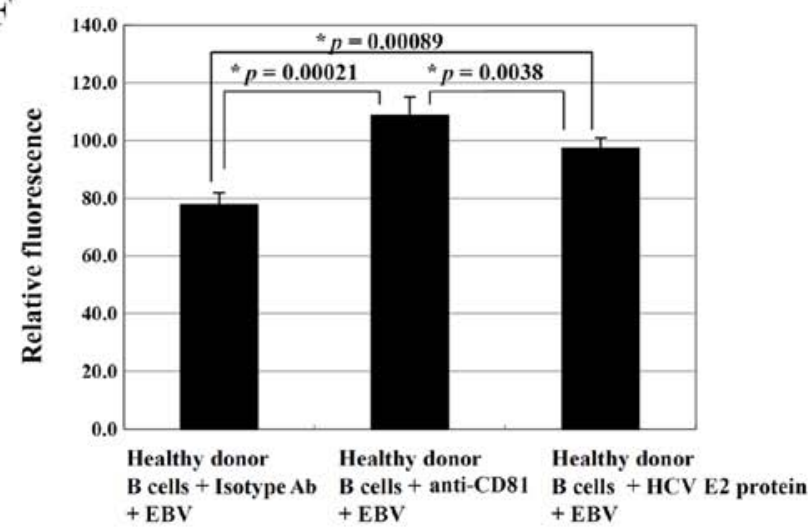

Figure 2. Clumping and proliferation of CD81 pre-stimulated B cells during Epstein-Barr virus (EBV) transformation. Following the treatment of PBMCs, the cells were infected with EBV. Cell clumping formation was monitored daily and measured at the indicated time periods (days 2 and 4, and weeks 1,2,3 and 4) using an inverted microscope. (A) EBV-transformed B cells from HCV-positive patients in comparison with EBV-infected B cells from normal controls. (B-D) B cells from healthy donors treated with several CD81 stimuli, including (B) anti-CD81 mAb $(10 \mu \mathrm{g} / \mathrm{ml}),(\mathrm{C})$ hepatitis C virus (HCV) E2 protein (2 $\mu \mathrm{g} /$ $\mathrm{ml}$ ), (D) serum from HCV-positive patients prior to EBV infection. MOPCs were used as isotype control antibodies (10 $\mu \mathrm{g} / \mathrm{ml})$. (E) At 2 weeks following EBV infection, EBV-transformed B cells from healthy donors or HCV patients were transferred and cultured for $48 \mathrm{~h}$. To analyze the proliferation rate, alamarBlue dye was added to each well (10\% by volume) and relative fluorescence was measured $7 \mathrm{~h}$ later using a fluorometer. Data represent the means \pm SEM of triplicate cultures. (F) At 2 weeks following EBV infection, CD81 pre-stimulated EBV-transformed B cells from healthy donors were transferred and cultured for $48 \mathrm{~h}$, and then the proliferation rate was analyzed as described above. Data represent the means \pm SEM of triplicate cultures. Comparisons between all individual data were made using one-way ANOVA. Results are representative of 5 separate experiments. 

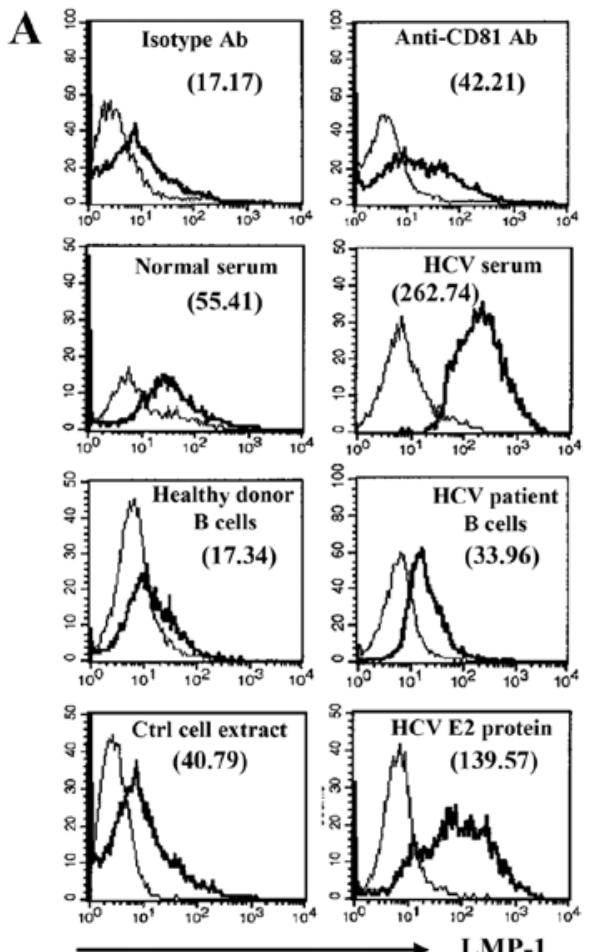

()$=$ MFI
B
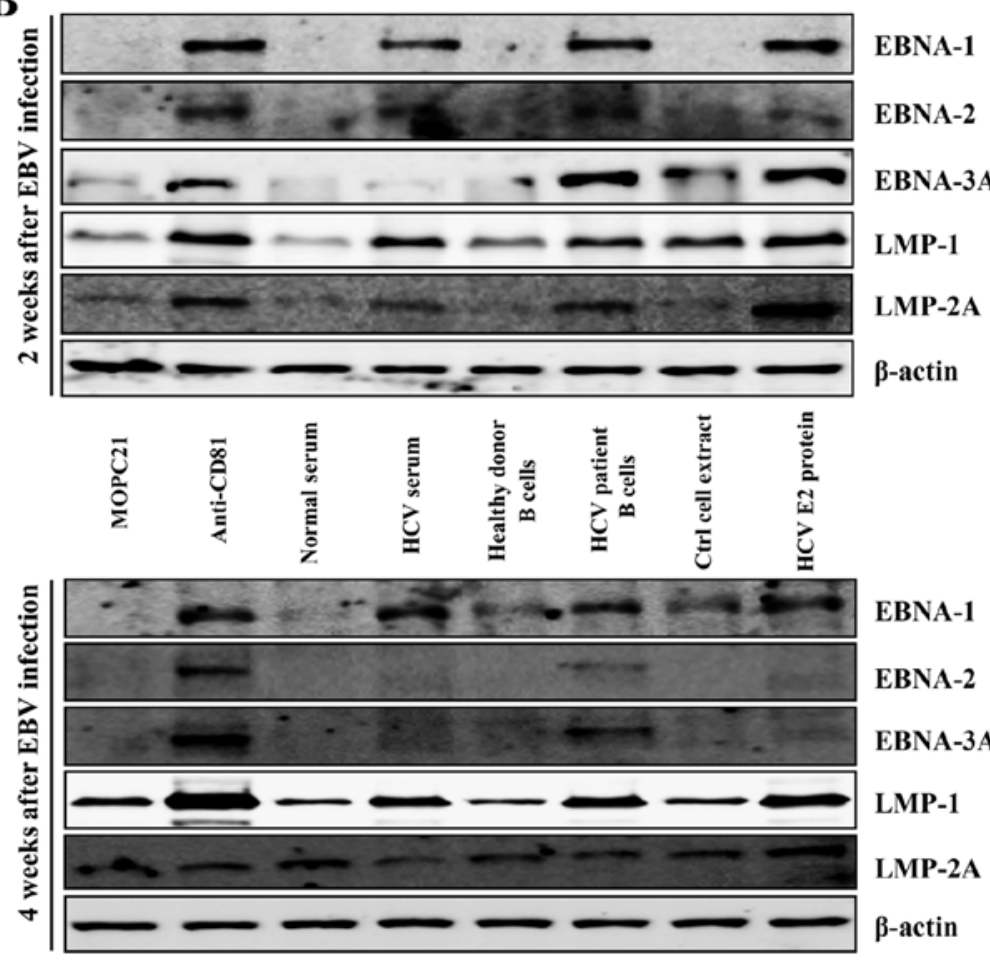

EBNA-1

EBNA-2

EBNA-3A

LMP-1

LMP-2A

$\beta$-actin

Figure 3. Effects of CD81 signaling in Epstein-Barr virus (EBV)-transformed B cells on the expression of intracellular EBV-induced proteins. (A) At 2 weeks following EBV infection of cells pre-treated with various treatments associated with CD81 signaling, EBV-transformed B cells were harvested and stained with a intracellular latent membrane protein-1 (LMP-1) antibody as described in the Materials and methods [thin line, mouse isotype PE control IgG2 antibody (MOPC21); thick line, LMP-1]. The percentage of positive cells and mean fluorescence intensities (MFIs; in parentheses) are denoted. (B) Western blot analysis was performed to monitor the EBV-induced proteins, such as EBNA-1, EBNA-2, EBNA-3A, LMP-1 and LMP-2A, at 2 and 4 weeks following the EBV infection of cells pre-treated with various treatments associated with CD81 signaling. Results represent 3 independent experiments.

CD81 pre-stimulation by cross-linking or treatment with $H C V$ E2 protein increases the proliferation of EBV-infected $B$ cells. HCV E2 induces the proliferation of resting B cells through interaction with CD81 (28). CD81 expression is also significantly higher in lymphocytes from HCV-positive patients than those from controls (18). In this study, to investigate the effect of stimulation with CD81 on the proliferation of EBV-transformed B cells, B cells isolated from normal healthy donors or HCV-positive patients were infected with EBV. A total of 7 healthy donors and 7 patients with chronic HCV infection were selected and examined. The clinical and virological characteristics of the patients with chronic HCV are presented in Table I. Early signs of EBV-induced transformation (cell aggregation, increased cell size and a sudden increase in growth) were observed in the B cells isolated from $\mathrm{HCV}$-positive patients 4 or 5 days following EBV infection. In addition, there was an increase in the number and size of B cell aggregations in the cells isolated from $\mathrm{HCV}$-infected patients compared with the $\mathrm{B}$ cells isolated from the normal controls (Fig. 2A). To determine whether $\mathrm{HCV}$ infection influences EBV-induced B cell transformation, we stimulated the B cells from healthy donors with anti-CD81 mAb, $\mathrm{HCV}$ E2 protein, or serum from $\mathrm{HCV}$-positive patients prior to EBV infection. Notably, all the EBV-induced transformation processes in the B cells pre-stimulated with anti-CD81 mAb, $\mathrm{HCV}$ E2 protein, or serum from HCV-positive patients occurred much more rapidly than those in the control cells (Fig. 2B-D). The alamarBlue proliferation assay revealed that the proliferation rate of the B cells isolated from HCV-positive patients ( $p=0.00037$, healthy donor PBMCs vs. HCV patient PBMCs), or CD81-prestimulated B cells from healthy donors $(p=0.00089$, healthy donor B cells stimulated with isotype control antibodies and EBV vs. healthy donor B cells stimulated with HCV E2 protein and EBV) was significantly enhanced at 2 weeks following EBV infection (Fig. 2E and F). These results suggest that HCV infection affects the transformation and proliferation of $B$ cells following EBV infection.

CD81 pre-stimulation promotes the proliferation of $B$ cells following $E B V$ infection through the early induction of $E B V$-induced protein and $I L-10$ expression. EBV-induced protein expression is upregulated following EBV infection. LMP-1 of EBV has been shown to induce the expression of a number of important cellular genes that have profound effects on cellular growth (29). In this study, to investigate the effects of CD81 stimulation on the proliferation of EBV-transformed B cells, we examined intracellular EBNA-1, EBNA-2, EBNA-3A, LMP-1 and LMP-2A expression in the EBV-transformed B cells. LMP-1 expression in EBV-infectedcells from $\mathrm{HCV}$-positive patients was significantly higher than that in healthy donor B cells (Fig. 3A). Pre-stimulation of CD81 with serum from obtained HCV-positive patients, HCV E2 protein, or anti-CD81 mAb accelerated the expression of LMP-1 in comparison with the respective controls (Fig. 3A). We also performed western blot analyses to determine the expression of EBV-induced proteins, which are involved in immortalization and growth. CD81 stimulation with anti-CD81 mAb, HCV E2 
A
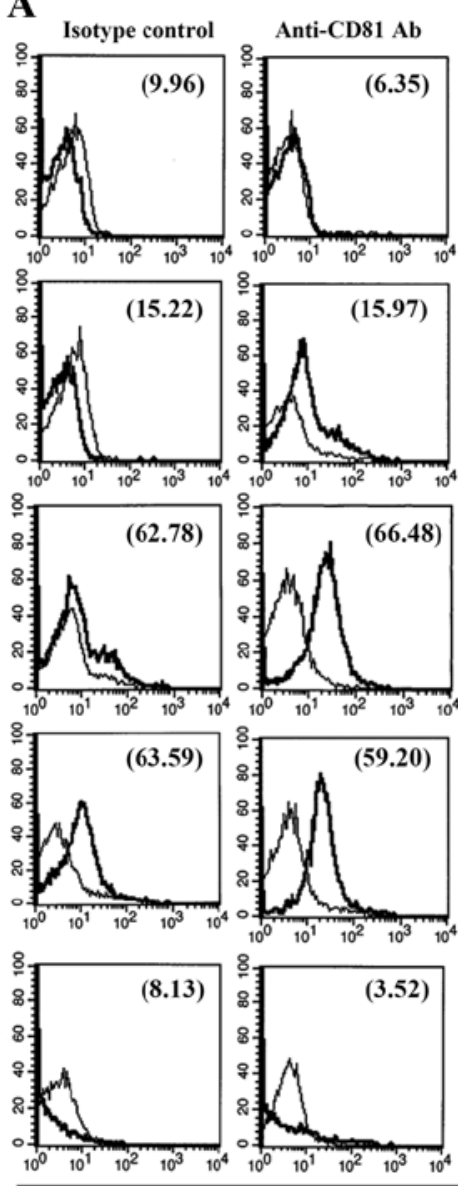

( ) = MFI

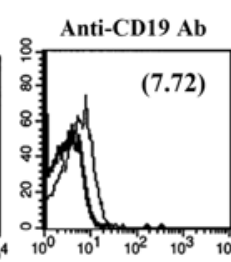

Before

EBV

infection
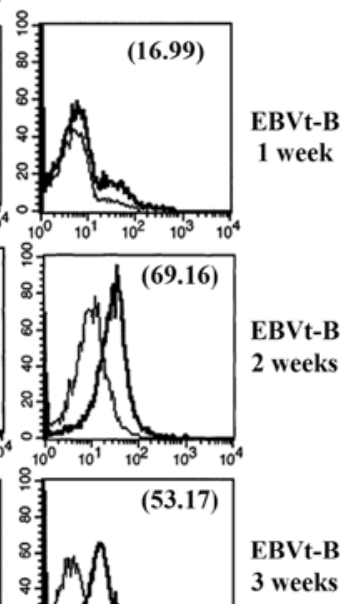

B

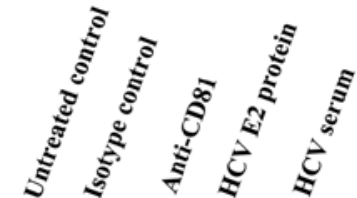

EBVt-B

2 weeks
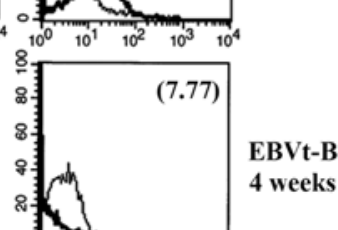

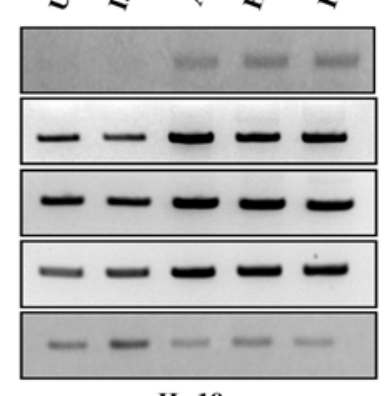

IL-10
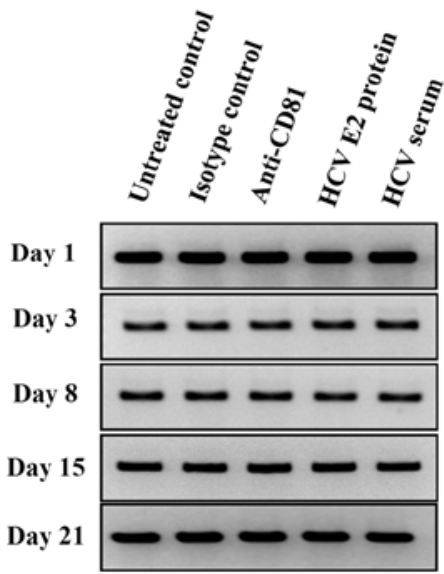

$\beta$-actin

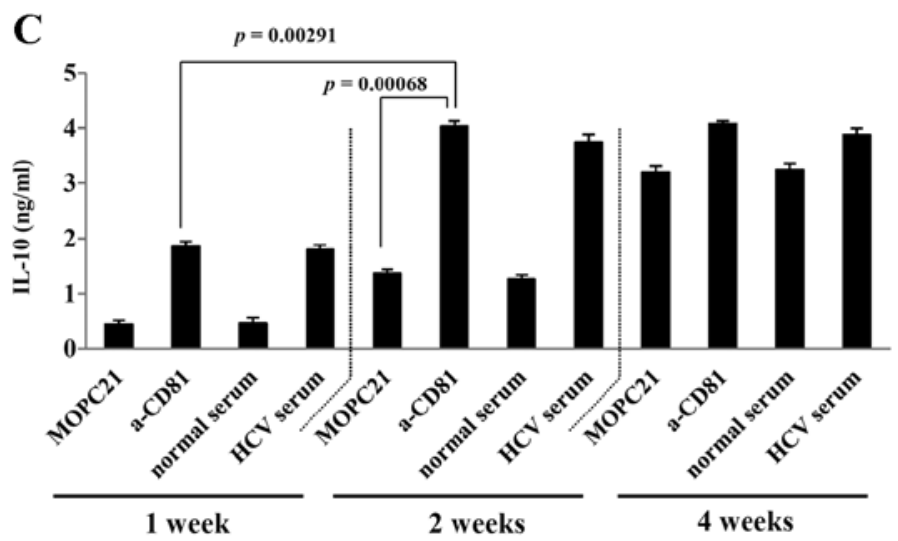

Figure 4. Effects of CD81 signaling in Epstein-Barr virus (EBV)-transformed (EBVt) B cells on IL-10 transcription and production. (A) B cells treated with anti-CD81 mAb prior to EBV infection were harvested each week for 4 weeks to analyze changes in intracellular IL-10 expression (thin line, mouse isotype PE control IgG1 antibody; thick line, IL-10). The percentage of positive cells and mean fluorescence intensities (MFIs; in parentheses) is denoted. (B) Total RNA was extracted at the indicated time points from EBV-transformed B cells treated with several CD81 stimuli prior to EBV infection and cDNA was synthesized for RT-PCR to measure the IL-10 transcript levels. (C) Cell culture supernatants were collected after 1, 2 and 4 weeks. IL-10 production was measured by ELISA assay. Data are presented as the mean of 3 independent experiments and error bars represent SEM of the means. Comparisons between all individual data were made using one-way ANOVA.

protein, or serum obtained from HCV-positive patients prior to EBV infection induced the early and high expression of EBV-induced EBNA-1, EBNA-2, EBNA-3A, LMP-1 and LMP-2A compared with that of the control group at 2 weeks. EBNA-1, LMP-1 and LMP-2A expression was maintained at significantly high levels following CD81 stimulation at 4 weeks (Fig. 3B).

The expression of LMP-1 induces the expression of human IL-10 in transfected sublines of the EBV-negative DG75 and BL41 cell lines, and IL-10 can also induce the expression of LMP-1 in B lymphocytes and in Burkitt's lymphoma $(30,31)$. Next, we examined the effects of CD81 stimulation on IL-10 production by EBV-transformed B cells. The IL-10 level was measured following CD19 stimulation with anti-CD19 mAb in EBV-transformed B cells. Pre-stimulation of CD81 with anti-CD81 $\mathrm{mAb}$ promoted the intracellular IL-10 expression at an earlier time point in the EBV-transformed B cells than in the unstimulated cells (Fig. 4A). We also observed that human IL-10 mRNA expression and protein secretion increased rapidly in the EBV-transformed B cells following pre-stimulation of CD81 (Fig. 4B and C). These results suggest that the stimuli associated with CD81 signaling induces the early expression of EBV-induced proteins, and that the increased IL-10 protein expression facilitates the survival and proliferation of EBV-transformed B cells.

ROS and caspases contribute to the apoptosis of $E B V$-transformed $B$ cells following the induction of the overexpression of $C D 81$. The above-mentioned results indicated that CD81 was upregulated by EBV infection. In addition, B cells pre-stimulated with various CD81 stimuli proliferated more rapidly following EBV infection than the healthy donor $\mathrm{B}$ cells through the production of LMP-1 and IL-10. However, the overexpression of CD81 by EBV-transformed B cells through stimulation with HCV E2 protein or anti-CD81 mAb inhibited cell proliferation (data not shown). In addition, we observed that the IL-10 mRNA level decreased abruptly at 3 or 4 weeks following CD81 stimulation, and the intracellular IL-10 protein level also dropped (Fig. 4A, lowest panel; Fig 4B, lowest lane). To investigate whether the overexpression of CD81 affects B cell survival and apoptosis, B cells transformed with EBV for 4 weeks and overexpressing CD-81 were stimulated with 

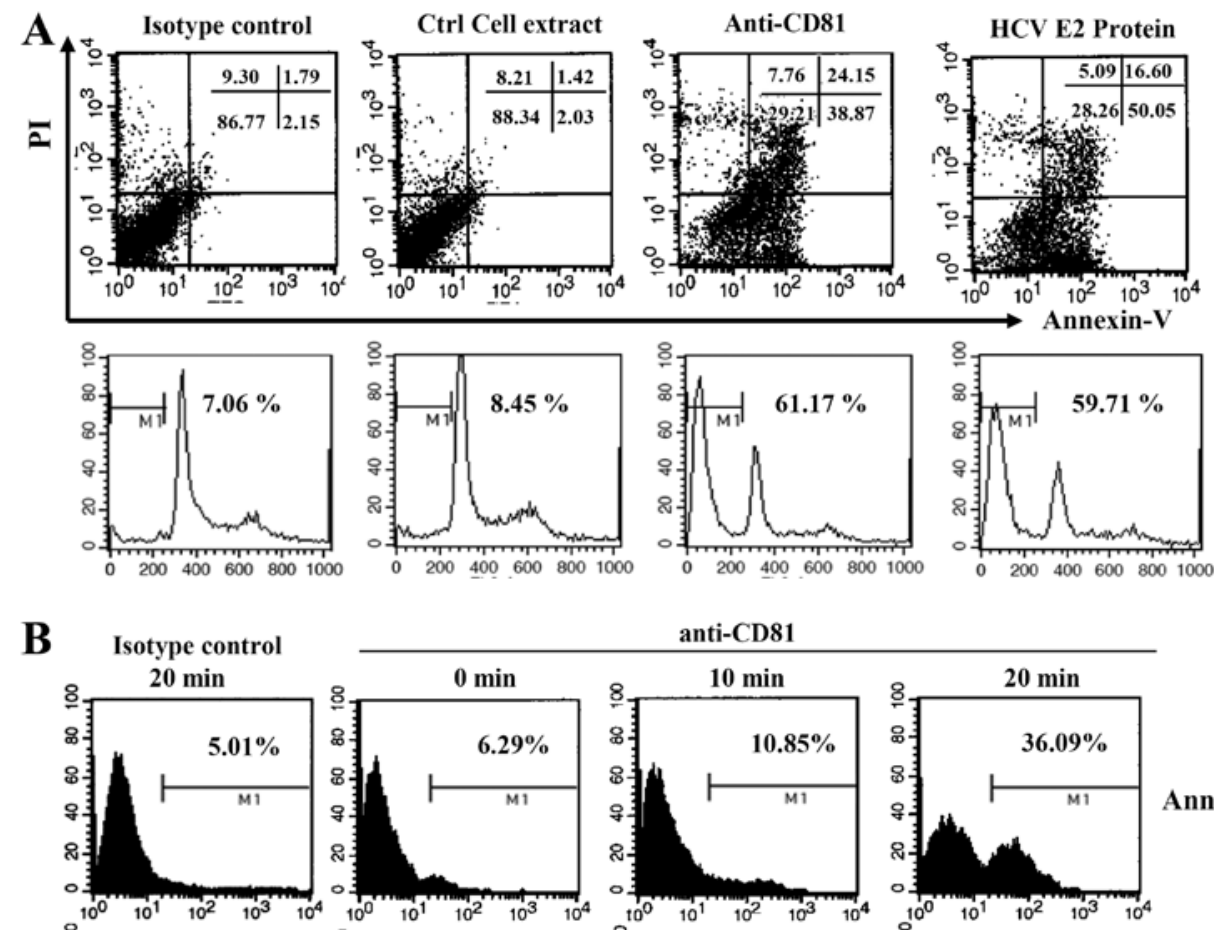

Annexin-V
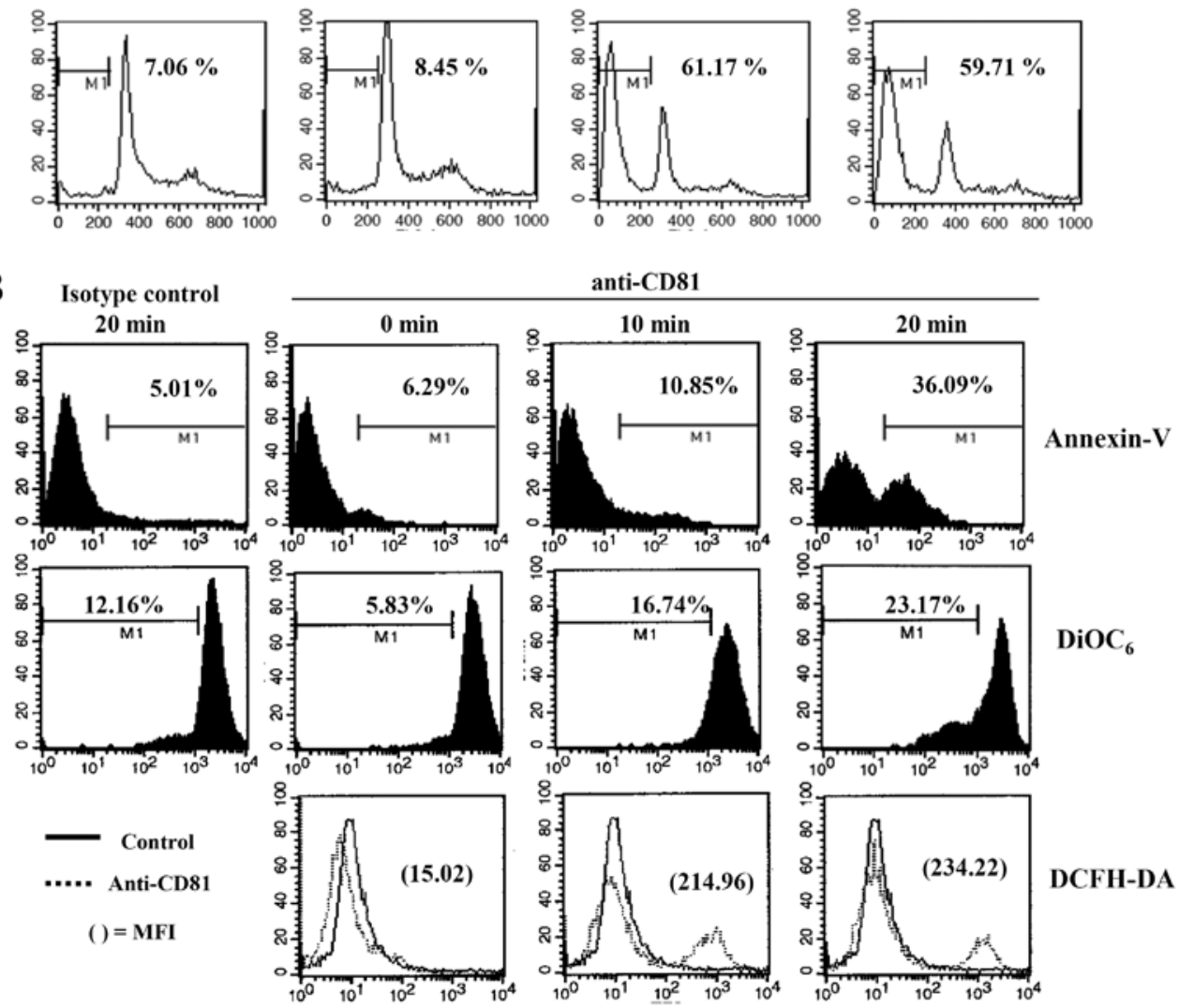

Figure 5. Apoptosis and cell cycle arrest of Epstein-Barr virus (EBV)-transformed B cells due to enhanced CD81 expression. At 4 weeks following EBV infection, EBV-transformed B cells were stimulated with immobilized anti-CD81 antibody, isotype control antibody, or HCV E2 protein under each of the indicated conditions as described in the Materials and methods. (A) Cells were harvested $\left(10^{6}\right.$ cells/200 $\left.\mu \mathrm{l}\right)$ and then stained with a FITC-conjugated anti-Annexin V monoclonal antibody $(\mathrm{mAb})$ and propidium iodide $(\mathrm{PI})$. The numbers in each quadrant represent percentages. Another set of EBV-transformed B cells were harvested and stained with PI (final concentration, $50 \mu \mathrm{l} / \mathrm{ml}$ ) for $15 \mathrm{~min}$ and analyzed by flow cytometry. Percentages of G1 phase cells are shown in this figure. (B) EBV-transformed B cells incubated in anti-CD81 or MOPC (isotype control) antibody-coated plates for the indicated times. Cells were harvested and stained with various fluorescent materials to detect intracellular changes in expression. Annexin V-positive cell number, ROS production, and mitochondrial membrane potential were determined as described in the Materials and methods. The results are representative of 3 separate experiments.

anti-CD81 mAb or HCV E2 protein. This induced the apoptosis of the EBV-transformed B cells. In addition, cell cycle analysis revealed that the stimulation with anti-CD81 $\mathrm{mAb}$ or HCV E2 resulted in a significant increase in the subG1 arrest of EBV-transformed B cells (Fig. 5A).

We then examined whether this CD81-mediated apoptosis is related to ROS production and the disruption of $\Delta \psi \mathrm{m}$, as caspases and ROS are important mediators of apoptosis following cross-linking with antibodies (32). The induction of the overexpression of CD81 on EBV-transformed B cells resulted in the immediate generation of ROS, it increased the number of Annexin V-positive apoptotic cells, and disrupted $\Delta \psi \mathrm{m}$ (Fig. 5B). The EBV-transformed B cells were preincubated with a pan-caspase inhibitor, Z-VAD-fmk, or a ROS quencher, NAC, for $2 \mathrm{~h}$ prior to CD81 stimulation with anti-CD81 mAb.Z-VAD-fmk and NAC significantly decreased CD81-dependent apoptosis and ROS generation by blocking the disruption of $\Delta \psi \mathrm{m}$ (Fig. 6A). In addition, treatment with antimycin A (300 $\mu \mathrm{M})$, a mitochondrial complex III inhibitor, also completely blocked the apoptosis of EBV-transformed $\mathrm{B}$ cells induced by the enhanced expression of CD81 (Fig. 6B). These results suggest that CD81-mediated apoptosis in EBV-transformed B cells may be related to ROS generation and may be dependent on the disruption of $\Delta \psi \mathrm{m}$.

CD81-mediated apoptosis of EBV-transformed B cells is mediated by the translocation of mitochondrial proteins. Based on our observation that Z-VAD-fmk, a pan-caspase inhibitor, incompletely blocked CD81-mediated apoptosis, we investigated whether the apoptosis mediated by the overexpression of CD81 is related to individual caspase activity and other apoptotic proteins released from the mitochondria. The EBV-transformed B cells were incubated with the caspase-8 inhibitor, Z-IETD, or the caspase-3 inhibitor, Z-DEVD, for 
A
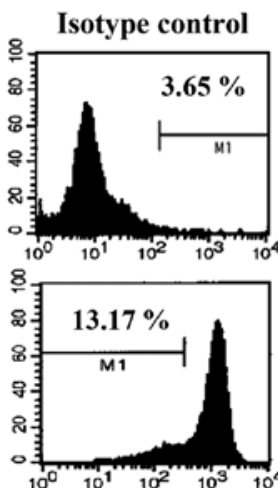

Control

..... Anti-CD81

( ) = MFI

B
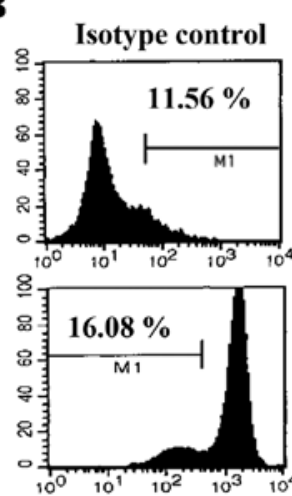

Control
$\ldots . .$.
Anti-CD81

( ) = MFI
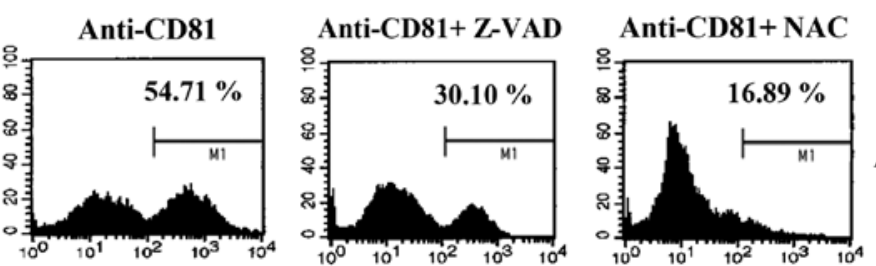

Annexin-V
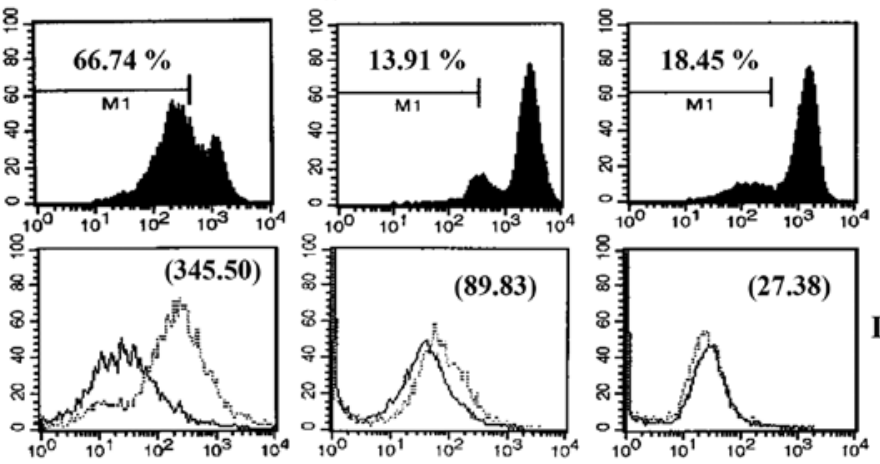

$\mathrm{DiOC}_{6}$

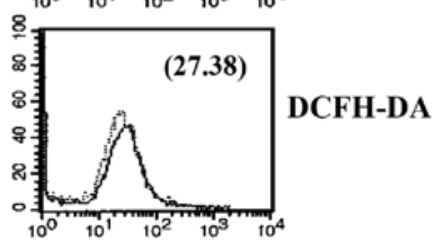

Anti-CD81
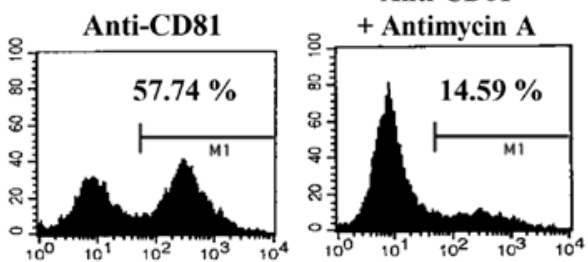

Annexin-V
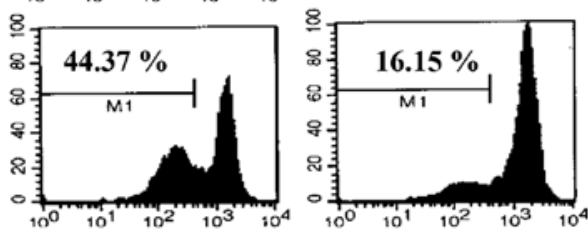

$\mathrm{DiOC}_{6}$

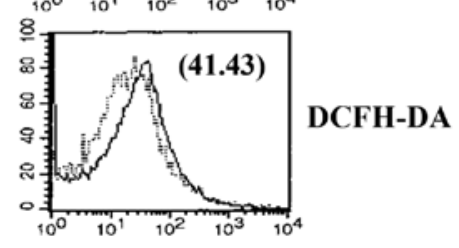

Figure 6. Effects of various inhibitors on CD81-mediated apoptosis of Epstein-Barr virus (EBV)-transformed B cells. At 4 weeks following EBV infection,

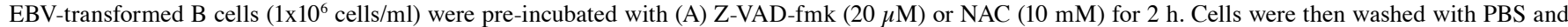
incubated further $\left(5 \times 10^{5}\right.$ cells/well, $\left.200 \mu \mathrm{l}\right)$ with anti-CD81- or MOPC antibody-coated $\left(5 \mu \mathrm{g} /\right.$ well) plates for $1 \mathrm{~h}$. (B) EBV-transformed B cells $\left(1 \times 10^{6}\right.$ cells/ml) were incubated with antimycin A $(300 \mu \mathrm{M})$ for 30 min prior to stimulation with anti-CD81 mAb to assess mitochondrial dysfunction. The Annexin V-positive cell number, ROS production, and mitochondrial membrane potential were determined as described in the Materials and methods. Results are representative of 3 separate experiments.

$2 \mathrm{~h}$ prior to CD81 stimulation. Pre-treatment with Z-IETD partially reduced CD81-mediated apoptosis; by contrast, pretreatment with Z-DEVD completely blocked CD81-mediated apoptosis (Fig. 7A). We subsequently examined the expression of the cleaved forms of caspase- 8 , caspase- 3 and PARP by western blot anlaysis. The EBV-transformed B cells stimulated with anti-CD81 mAb exhibited cleaved PARP and generated the active cleaved forms of caspase-3 (17/19-kDa fragments), indicating the induction of apoptosis. However, 41/43-kDa fragments corresponding to the initial form of caspase- 8 were observed. The untreated or NAC pre-treated EBV-transformed B cells only expressed precursor proteins (Fig. 7B). Thus, we performed confocal microscopy analysis using anticytochrome $c$ antibody to determine the apoptotic proteins released from the mitochondria. Stimulation with anti-CD81 $\mathrm{mAb}$ caused the translocation of cytochrome $c$ from the mitochondria to the cytosol in the EBV-transformed B cells. By contrast, treatment with Z-VAD-fmk and NAC prior to stimulation with anti-CD81 mAb almost completely blocked the release of cytochrome $c$ from the mitochondria (Fig. 7C). These results suggest that the CD81-mediated signal results in the release of apoptotic molecules, mainly from the mitochondria and the activation of the caspase-3 pathway.

JNK-associated Bcl-2 pathway is involved in CD81-mediated apoptosis. To investigate the mechanisms responsible for the apoptosis mediated by the overexpression of CD81, we examined certain candidate signaling molecules by RT-PCR for the detection of RNA derived from EBV-transformed B cells. Bax, Bad and Bcl-2 mRNA was constitutively expressed in the EBV-transformed B cells, but CD81 cross-linking increased the mRNA expression of Bax and Bad, which are known pro- 

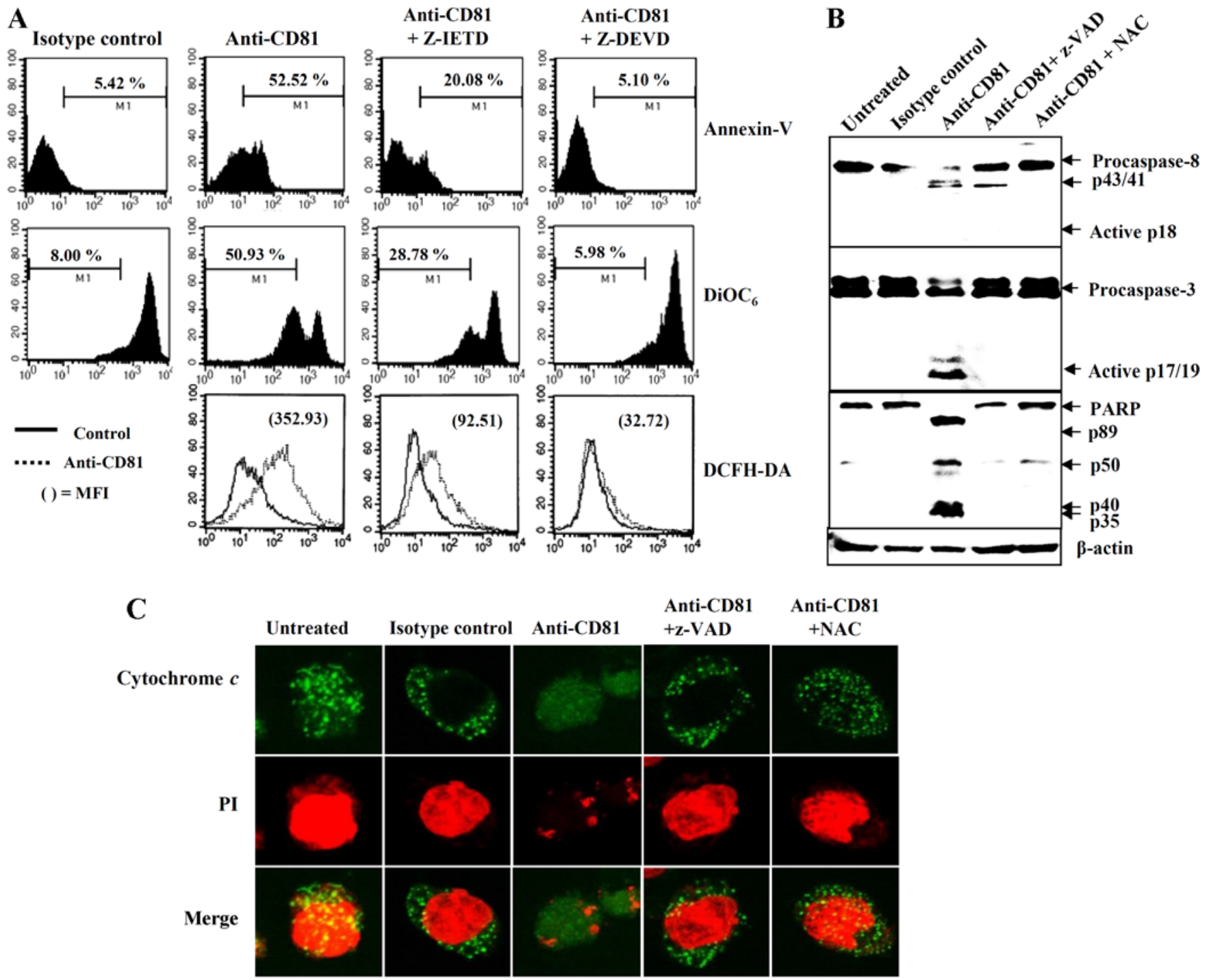

Figure 7. Effects of caspase inhibition and ROS inhibition on CD81-mediated apoptosis of Epstein-Barr virus (EBV)-transformed B cells. (A) At 4 weeks following EBV infection, EBV-transformed B cells ( $1 \times 10^{6}$ cells $\left./ \mathrm{ml}\right)$ were incubated with Z-IETD-fmk $(20 \mu \mathrm{M})$ or Z-DEVD-fmk $(20 \mu \mathrm{M})$ for $2 \mathrm{~h}$. Cells were then washed with PBS and incubated further $\left(5 \times 10^{5}\right.$ cells/well, $\left.200 \mu \mathrm{l}\right)$ in anti-CD81- or MOPC antibody-coated (5 $\mu \mathrm{g} /$ well) plates for $1 \mathrm{~h}$. Annexin V-positive cell number, ROS production and mitochondrial membrane potential were determined as described in the Materials and methods. (B and C) EBV-transformed B cells $\left(1 \times 10^{6}\right.$ cells/ml) were pre-incubated with Z-VAD-fmk $(20 \mu \mathrm{M})$ or NAC $(10 \mathrm{mM})$ for $2 \mathrm{~h}$ before stimulation with anti-CD 81 antibody. Some cells were harvested and lysed in lysis buffer for western blot analysis of caspase-3, caspase-8 and PARP in whole lysates as described in the Materials and methods. Other cells were harvested and permeabilized with $0.1 \%$ saponin in PBS. FITC-conjugated anti-cytochrome $c$ was used to detect mitochondrial apoptotic molecules. Nuclei were stained with propidium iodide (PI). Cells were then observed under a confocal microscope (x400 magnification). Results are representative of 3 separate experiments.

apoptotic genes (Fig. 8A, 1st and 2nd panels from the top). By contrast, the expression of Bcl-2, an anti-apoptotic gene, was decreased by CD81 stimulus (Fig. 8A, 3rd panel from the top). NAC almost completely blocked the CD81-mediated changes in the expression levels of apoptosis-associated genes (Fig. 8A, lane 4). However, the broad-spectrum caspase inhibitor, Z-VAD-fmk did not inhibit the CD81-mediated upregulation of Bax and Bad in the EBV-transformed B cells. To elucidate the identity of the upstream proteins in the CD81-mediated mitochondrial apoptotic pathway, we examined the expression levels of JNK, c-Jun, ERK1/2 and Akt, which mediate signaling to members of the Bcl-2 family $(33,34)$. CD81 stimulation upregulated the expression of the phosphorylated form of JNK and its major substrate, the phosphorylated form of c-Jun (Fig. 8B, panels 5 and 7 from the top), whereas it decreased the expres- sion of the phosphorylated forms of ERK1/2 and Akt relative to the control cells (Fig. 8B, panels 1 and 3 from the top). NAC almost completely blocked the CD81-mediated changes in the phosphorylation of the kinases (Fig. 8B, lane 5). These results suggest that the apoptosis-associated genes of EBV-transformed B cells, stimulated by CD81, are regulated by MAPK signaling.

\section{Discussion}

Although previous studies have confirmed the specificity of binding between E2 and CD81, these studies were not able to fully explain the effect of overexpressed CD81 on EBV-transformed B cells $(35,36)$. In this study, the pattern of CD81 expression in EBV-infected B cells during transformation remained unaltered for the first 3 weeks; however, there 
A

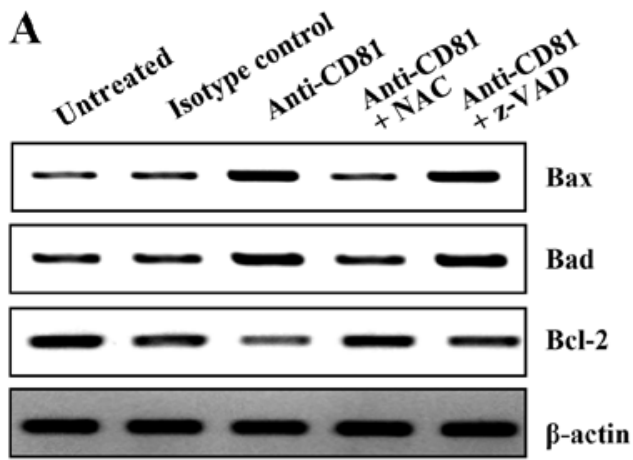

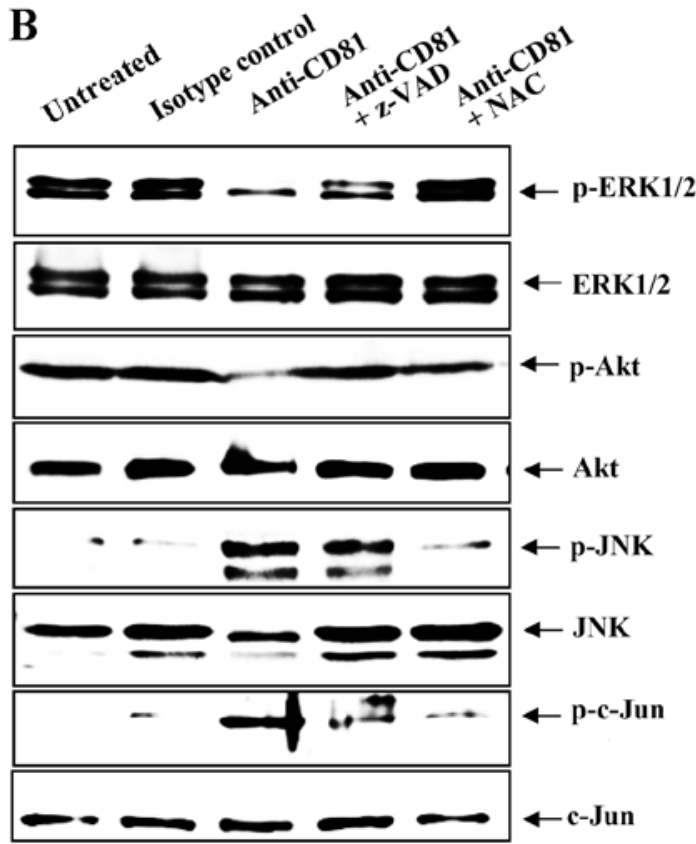

B

Figure 8. Bcl-2 family and MAPK signaling are associated with the mitochondrial apoptotic pathway in Epstein-Barr virus (EBV)-transformed B cells following CD81 stimulation. EBV-transformed B cells $\left(1 \times 10^{6}\right.$ cells $\left./ \mathrm{ml}\right)$ were incubated with Z-VAD-fmk $(20 \mu \mathrm{M})$ or NAC $(10 \mathrm{mM})$ for $2 \mathrm{~h}$. Cells were then washed with PBS and incubated further $\left(5 \times 10^{5}\right.$ cells/well, $\left.200 \mu \mathrm{l}\right)$ with anti-CD81- or isotype antibody-coated $(5 \mu \mathrm{g} /$ well $)$ plates for $1 \mathrm{~h}$ using the same conditions as described in the previous experiments. (A) Total RNA was extracted, and cDNA was synthesized for RT-PCR. RT-PCR was performed to investigate transcript levels of Bax, Bad and Bcl-2. (B) Western blot analysis was performed to monitor the phosphorylation of the survival factor-related proteins (ERK1/2, Akt) and death stimuli-related proteins (JNK, c-Jun). Results are representative of 3 separate experiments.

was a rapid increase in CD81 expression at the fourth week following EBV infection. Resting peripheral blood B cells stimulated with HCV envelope protein E2, as well as anti-CD81 $\mathrm{mAb}$ exhibited an enhanced proliferation and transformation following EBV infection. By contrast, the induction of the overexpressin of CD81 on EBV-transformed B cells induced apoptosis and increased the subG1 peak in cell cycle analysis. Previous studies have demonstrated that the multimeric engagement of CD81 is required for the activation of resting B cells (28) and for the protection of primary human B lymphocytes from Fas-mediated apoptosis (24). However, the results of our study suggest that CD81 signaling is transmitted through different mechanisms in resting B cells and EBV-transformed B cells (Fig. 9).

CD81 is a cellular ligand for E2 that is expressed by most human cell types, but not by red blood cells or platelets (13). It is known that this complex reduces the threshold for B cell activation via the BCR by bridging Ag-specific recognition and CD21-mediated complement recognition (2,37). A statistically significant increase in CD81 expression has been observed on lymphocytes and monocytes from $\mathrm{HCV}$-positive patients as compared with healthy controls (18). The engagement of CD81 has been shown to result in an increased percentage of B cells expressing the early activation marker, CD69, the transferrin receptor, $\mathrm{CD} 71$, and the co-stimulatory molecule, CD86 (28). For these reasons, in this study, B cells derived from patients with HCV were pre-activated chronically compared with the cells from normal healthy donors. We also observed that the EBV transformation process of B cells isolated from HCV-positive patients occurred more rapidly than that of B cells isolated from normal controls in this study. In addition, the proliferative activity of the EBV-transformed B cells isolated from HCV-positive patients surpassed that of the normal controls. This acceleration of the EBV transformation process also occurred in healthy donor B cells that were stimulated with serum obtained from HCV-positive patients, HCV E2 protein, or anti-CD81 mAb prior to EBV infection. However, we could not exclude the possibility that contamination with other blood components had occurred in the stimulation with serum obtained from HCV-positive patients. Thus, anti-CD81 $\mathrm{mAb}$ was used for CD81 stimulation in the experiment shown in Fig. 5 and thereafter.

In previous studies, it has been observed that the time required for EBV transformation is shortened by CD19 crosslinking through earlier intracellular LMP-1, EBNA-1 and EBNA-2 expression than in the controls (38), and that EBV infection induces the expression of LMP-1, which promotes B cell immortalization (39). The upregulation of constitutive nuclear factor $\mathrm{NF}-\kappa \mathrm{B}$, as well as CD30, CD40, tumor necrosis factor (TNF)- $\alpha$, and Notch1 interactions contributes to these processes (30). CD81 signaling of resting B cells was accelerated during transformation into EBV-induced lymphoblastoid $B$ cells in this study. We observed that EBV-specific proteins (LMP-1, LMP-2A, EBNA-1, EBNA-2 and EBNA-3A) and human IL-10 expression increased during the early period of the EBV transformation of CD81 pre-stimulated B cells compared with the unstimulated controls. EBNA-1 and EBNA-2 are required for $\mathrm{B}$ cell immortalization. LMP-1 is a direct target of EBNA-2 (40). CD19 and BCR ligation has been demonstrated to increase the mRNA expression of EBNA-1 and EBNA-2 in the early stages of infection (38). For these reasons, we hypothesized that EBNA-2 may be a more important factor than 


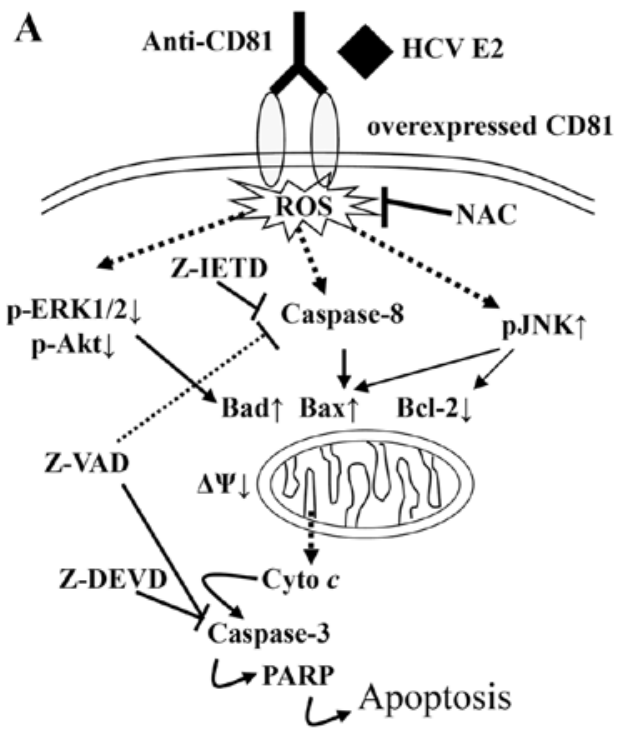

EBV-transformed B cell

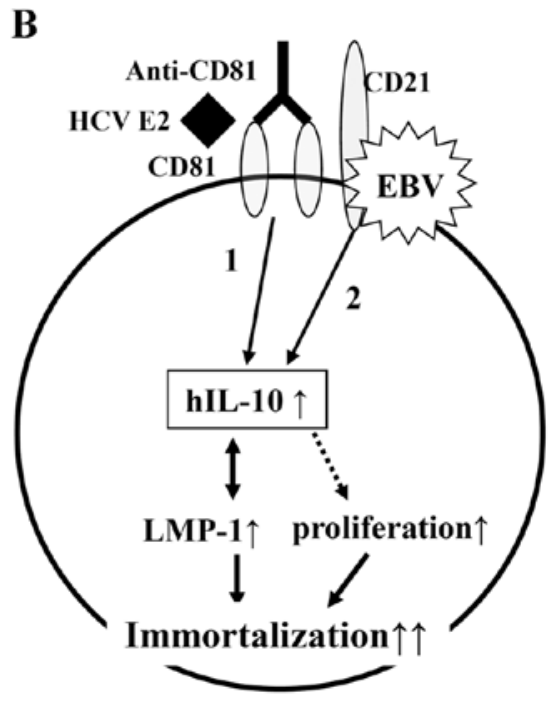

Resting B cell

Figure 9. Schematic representation of the effects of CD81-induced signaling on Epstein-Barr virus (EBV)-transformed B cells and resting B cells. (A) Signaling through overexpressed CD81 induces apoptosis of EBV-transformed B cells through ROS production and mitochondrial dysfunction. (B) Pre-stimulation through CD81 plus EBV infection induces the transcription of human interleukin (IL)-10, resulting in the rapid upregulation of latent membrane protein (LMP)-1 expression and the rapid establishment of immortalization.

EBNA-1. However, CD81 stimulation significantly increased and maintained EBNA-1 expression levels compared with EBNA-2 and EBNA-3A in EBV-transformed B cells. These results suggest that proliferation and $\mathrm{EBV}$ transformation are accelerated through different mechanisms by CD81 signaling prior to EBV infection and that CD81 signaling is initiated and maintained by $\mathrm{HCV}$ infection in vivo.

Both EBV and HCV bind to the same cell surface protein complex to deliver stimulatory signals to B cells. This complex contains CD21 which binds EBV, and CD81 which binds E2 (13). In a previous study, EBV was detected in $37 \%$ of HCC cases in Japan and EBV DNA is also frequently found in cases with HCV (41). However, another group reported that of $31 \mathrm{HCC}$ cases, none were positive for EBV while $10(32 \%)$ tested positive for $\mathrm{HCV}$ and 12 (38\%) tested positive for hepatitis B virus (HBV) (42). These data suggest that EBV infection may cooperate with $\mathrm{HCV}$ infection; however, the association between these two viruses needs to be investigated further.

In patients chronically infected with $\mathrm{HCV}$, the cell surface tetraspanin CD81 is overexpressed by different PBMC subtypes compared with healthy controls. CD81 expression by PBMCs, including $\mathrm{CD}^{+}, \mathrm{CD}^{+}, \mathrm{CD} 9^{+}$and $\mathrm{CD}^{+} 6^{+}$cells, has been shown to be downregulated during interferon $\alpha$-based antiviral therapy (43). In a prevoius study, patients with splenic lymphoma with villous lymphocytes and $\mathrm{HCV}$ infection who were treated with interferon $\alpha-2 b$ went into remission after the loss of detectable HCV RNA (44). In another study, cross-linking of CD81 on the cell surface of the EBV-positive lymphoblastoid cell line JY induced the release of TNF- $\alpha$ and homotypic aggregation and inhibited JY cell proliferation (45). However, the differential effects of normal or elevated CD81 on B cells are not yet fully understood due to the lack of a suitable model. For these reasons, in this study, we examined the effects of CD81 overexpression on the survival or apoptosis of EBV-transformed
B cells (normal expression vs. overexpression). EBV-infected B cells are known to resist Fas-mediated apoptosis due to defects in the proximal Fas signaling pathway (46) or the expression of the FLICE-inhibitory protein (FLIP) (47). We also observed that Fas and Fas ligand expression by EBV-transformed B cells was not altered following CD81 stimulation, and that apoptosis induced by CD81 cross-linking was not recovered by treatment of the cells with ZB4 antibody, which blocks Fas-mediated apoptosis (data not shown). Thus, we focused primarily on the mitochondria and ROS to elucidate the mechanisms responbisle for CD81-mediated apoptosis.

In the present study, we found that cross-linking CD81 on EBV-transformed B cells resulted in the immediate generation of ROS, which subsequently disrupted $\Delta \psi \mathrm{m}$. However, the precise mechanism of ROS generation remains unclear. ROS modulate cytoskeletal metabolism, intracellular $\mathrm{Ca}^{2+}$ levels, and influence the mitochondrial membrane directly or indirectly (48). It has been reported that ROS induce caspase activity, JNK phosphorylation, and even participate in ERK1/2 signaling $(33,49)$. These findings are supported by our observations that the ROS quencher, NAC, completely blocked apoptosis and ROS generation and that Z-VAD-fmk, a pan-caspase inhibitor, effectively blocked CD81-mediated apoptosis. In addition, blocking experiments using individual caspase inhibitors (Z-IETD and Z-DEVD) and the results from western blot analysis revealed that CD81 cross-linking induced apoptosis mainly via caspase- 3 and partly via caspase- 8 . These results indicate that CD81 signaling induces the apoptosis of EBV-transformed B cells through a caspase-dependent pathway. A previous study demonstrated that upstream regulators such as JNK, c-Jun, ERK1/2 and Akt transduce signals to members of the Bcl-2 family (33). However, the engagement of CD81 on human B cells by a combination of HCV E2 and an anti-CD81 $\mathrm{mAb}$ triggers the JNK pathway and leads to the preferential 
proliferation of the naïve B cell subset (28). Notably, stimulation through the overexpressio of CD81 also induced the phosphorylation of JNK and c-Jun, but repressed the phosphorylation of ERK1/2 and Akt to induce the apoptosis of EBV-transformed B cells. The expression of Bcl-2, regulated by the JNK pathway, was restored in EBV-transformed B cells treated with NAC prior to CD81 stimulation. These results suggest that stimulation of overexpressed CD81 on EBV-transformed B cells may initiate ROS production and activate the apoptotic signaling cascade through a JNK-mediated mitochondrial apoptotic pathway, as well as suppress survival signaling through inhibition of ERK1/2 and Akt phosphorylation.

Taken together, our results suggest that the normal expression of CD81 vs. the overexpression of CD81 has different effects on EBV-infected B cells. HCV is a lymphotrophic and a hepatotrophic virus (50). This unusual lymphotropism may, at least in part, induce the multiple immune-mediated extrahepatic manifestations of $\mathrm{HCV}$ infection, such as MC, the presence of serum rheumatoid factor (RF), and B cell non-Hodgkin lymphoma (9-11). However, the persistence of $\mathrm{HCV}$ infection results in CD81 overexpression and chronic stimulation of B cells (51). Our results suggest that CD81 overexpression may induce the eradication of activated $B$ cells producing immunoglobulin against $\mathrm{HCV}$ through apoptosis and may eventually lead to malignant transformation and the development of lymphoma by EBV. Our results provide insight into changes in the expression patterns of CD81 and the high prevalence of $\mathrm{B}$ cell proliferative disorders, including non-Hodgkin B cell lymphoma in HCV-positive patients. In addition, the results of the present study indicate potential targets for the treatment of EBV infection in HCV-positive patients.

\section{Acknowledgements}

The present study was supported by the Basic Science Research Program through the National Research Foundation of Korea (NRF) funded by the Ministry of Education (grant no. NRF-2013R1A1A2010668) and the National R\&D Program for Cancer Control, Ministry for Health, Welfare and Family Affairs, Republic of Korea (grant no. 0920040).

\section{References}

1. Bradbury LE, Kansas GS, Levy S, Evans RL and Tedder TF: The CD19/CD21 signal transducing complex of human B lymphocytes includes the target of antiproliferative antibody-1 and Leu-13 molecules. J Immunol 149: 2841-2850, 1992.

2. Matsumoto AK, Martin DR, Carter RH, Klickstein LB, Ahearn JM, and Fearon DT: Functional dissection of the CD21/CD19/TAPA-1/Leu-13 complex of B lymphocytes. J Exp Med Oct 178: 1407-1417, 1993.

3. Carter RH and Fearon DT: CD19: lowering the threshold for antigen receptor stimulation of B lymphocytes. Science 256 : 105-107, 1992.

4. Levy S, Todd SC and Maecker HT: CD81 (TAPA-1): a molecule involved in signal transduction and cell adhesion in the immune system. Annu Rev Immunol 16: 89-109, 1998.

5. van Zelm MC, Smet J, Adams B, Mascart F, Schandené L, Janssen F, Ferster A, Kuo CC, Levy S, van Dongen JJ, and van der Burg M: CD81 gene defect in humans disrupts CD19 complex formation and leads to antibody deficiency. J Clin Invest 120: 1265-1274, 2010.

6. Miyazaki T, Müller U and Campbell KS: Normal development but differentially altered proliferative responses of lymphocytes in mice lacking CD81. EMBO J 16: 4217-4225, 1997.
7. Tsitsikov EN, Gutierrez-Ramos JC and Geha RS: Impaired CD19 expression and signaling, enhanced antibody response to type II T independent antigen and reduction of B-1 cells in CD81-deficient mice. Proc Natl Acad Sci USA 94: 10844-10849, 1997.

8. Choo QL, Kuo G, Weiner AJ, Overby LR, Bradley DW and Houghton M: Isolation of a cDNA clone derived from a blood-borne non-A, non-B viral hepatitis genome. Science 244: 359-362, 1989.

9. Ferri C, La Civita L, Longombardo G, Zignego AL and Pasero G: Mixed cryoglobulinaemia: a cross-road between autoimmune and lymphoproliferative disorders. Lupus 7: 275-279, 1998.

10. Dammacco F, Sansonno D, Piccoli C, Racanelli V, D'Amore FP and Lauletta G: The lymphoid system in hepatitis $\mathrm{C}$ virus infection: autoimmunity, mixed cryoglobulinemia, and Overt B cell malignancy. Semin Liver Dis 20: 143-157, 2000.

11. Quinn ER, Chan CH, Hadlock KG, Foung SK, Flint M and Levy S: The B cell receptor of a hepatitis $\mathrm{C}$ virus (HCV)-associated non-Hodgkin lymphoma binds the viral E2 envelope protein, implicating HCV in lymphomagenesis. Blood 98: 3745-3749, 2001.

12. Machida K, Cheng KT, Pavio N, Sung VM and Lai MM: Hepatitis $C$ virus E2-CD81 interaction induces hypermutation of the immunoglobulin gene in B cells. J Virol 79: 8079-8089, 2005.

13. Pileri P, Uematsu Y, Campagnoli S, Galli G, Falugi F, Petracca R, Weiner AJ, Houghton M, Rosa D, Grandi G, and Abrignani S: Binding of hepatitis C virus to CD81. Science 282: 938-941, 1998.

14. Burlone ME and Budkowska A: Hepatitis $\mathrm{C}$ virus cell entry: role of lipoproteins and cellular receptors. J Gen Virol 90: 1055-1070, 2009.

15. Roccasecca R, Ansuini H, Vitelli A, Meola A, Scarselli E, Acali S, Pezzanera M, Ercole BB, McKeating J, Yagnik A, et al: Binding of the hepatitis C virus E2 glycoprotein to CD81 is strain specific and is modulated by a complex interplay between hypervariable regions 1 and 2. J Virol 77: 1856-1867, 2003.

16. Challine D, Buisson M, Cadilhac M, Germanidis G, Joab I, Eliaszewicz M, Caumes E, Flahault A, Fillet AM, Pawlotsky JM, and Seigneurin JM: Hepatitis $C$ virus-Epstein-Barr virus interaction in patients with AIDS. J Med Virol 67: 510-515, 2002.

17. Ferri C, Lo Jacono F, Monti M, Caracciolo F, La Civita L, Barsanti LA, Longombardo G, Lombardini F, Careccia G and Zignego AL: Lymphotropic virus infection of peripheral blood mononuclear cells in B cell non-Hodgkin's lymphoma. Acta Haematol 98: 89-94, 1997.

18. Roque-Cuéllar MC, Sánchez B, García-Lozano JR, GarridoSerrano A, Sayago M, Praena-Fernández JM, Núñez-Roldán A and Aguilar-Reina J: Expression of CD81, SR-BI and LDLR in lymphocytes and monocytes from patients with classic and occult hepatitis C virus infection. J Med Virol 84: 1727-1736, 2012.

19. Molina S, Castet V, Pichard-Garcia L, Wychowski C, Meurs E, Pascussi JM, Sureau C, Fabre JM, Sacunha A, Larrey D, et al: Serum-derived hepatitis $C$ virus infection of primary human hepatocytes is tetraspanin CD81 dependent. J Virol 82: 569-574, 2008

20. Petracca R, Falugi F, Galli G, Norais N, Rosa D, Campagnoli S, Burgio V, Di Stasio E, Giardina B, Houghton M, et al: Structure-function analysis of hepatitis $\mathrm{C}$ virus envelope-CD81 binding. J Virol 74: 4824-4830, 2000.

21. Fornasieri A, Bernasconi P, Ribero ML, Sinico RA, Fasola M, Zhou J, Portera G, Tagger A, Gibelli A and D'amico G: Hepatitis C virus (HCV) in lymphocyte subsets and in B lymphocytes expressing rheumatoid factor cross-reacting idiotype in type II mixed cryoglobulinaemia. Clin Exp Immunol 122: 400-403, 2000.

22. Sung VM, Shimodaira S, Doughty AL, Picchio GR, Can H, Yen TS, Lindsay KL, Levine AM and Lai MM: Establishment of B cell lymphoma cell lines persistently infected with hepatitis C virus in vivo and in vitro: the apoptotic effects of virus infection. J Virol 77: 2134-2146, 2003.

23. Brazzoli M, Bianchi A, Filippini S, Weiner A, Zhu Q, Pizza M and Crotta S: CD81 is a central regulator of cellular events required for hepatitis $\mathrm{C}$ virus infection of human hepatocytes. J Virol 82: 8316-8329, 2008.

24. Chen Z, Zhu Y, Ren Y, Tong Y, Hua X, Zhu F, Huang L, Liu Y, Luo Y, Lu W, et al: Hepatitis C virus protects human B lymphocytes from Fas-mediated apoptosis via E2-CD81 engagement. PLoS One 6: e18933, 2011.

25. Kim YS, Park GB, Lee HK, Song H, Choi IH, Lee WJ and Hur DY: Cross-linking of B7-H1 on EBV-transformed B cells induces apoptosis through reactive oxygen species production, JNK signaling activation, and fasL expression. J Immunol 181: 6158-6169, 2008 . 
26. Song H, Park G, Kim YS, Hur I, Kim H, Ryu JW, Lee HK, Cho DH, Choi IH, Lee WJ, and Hur DY: B7-H4 reverse signaling induces the apoptosis of EBV-transformed B cells through Fas ligand up-regulation. Cancer Lett 266: 227-237, 2008.

27. Heo TH, Chang JH, Lee JW, Foung SK, Dubuisson J and Kang CY: Incomplete humoral immunity against hepatitis $\mathrm{C}$ virus is linked with distinct recognition of putative multiple receptors by E2 envelope glycoprotein. J Immunol 173: 446-455, 2004.

28. Rosa D, Saletti G, De Gregorio E, Zorat F, Comar C, D'Oro U, Nuti S, Houghton M, Barnaba V, Pozzato G, and Abrignani S: Activation of naïve B lymphocytes via CD81, a pathogenetic mechanism for hepatitis C virus-associated B lymphocyte disorders. Proc Natl Acad Sci USA 102: 18544-18549, 2005.

29. Poppema S: Immunobiology and pathophysiology of Hodgkin lymphomas. Hematology Am Soc Hematol Educ Program 2005: 231-238, 2005

30. Nakagomi H, Dolcetti R, Bejarano MT, Pisa P, Kiessling R and Masucci MG: The Epstein-Barr virus latent membrane protein-1 (LMP1) induces interleukin-10 production in Burkitt lymphoma lines. Int J Cancer 57: 240-244, 1994

31. Kis LL, Takahara M, Nagy N, Klein G and Klein E: IL-10 can induce the expression of EBV-encoded latent membrane protein-1 (LMP-1) in the absence of EBNA-2 in B lymphocytes and in Burkitt lymphoma- and NK lymphoma-derived cell lines. Blood 107: 2928-2935, 2006.

32. Saelens X, Festjens N, Vande Walle L, van Gurp M, van Loo G and Vandenabeele P: Toxic proteins released from mitochondria in cell death. Oncogene 23: 2861-2874, 2004.

33. Wang M, Zhang L, Han X, Yang J, Qian J, Hong S, Samaniego F, Romaguera J and Yi Q: Atiprimod inhibits the growth of mantle cell lymphoma in vitro and in vivo and induces apoptosis via activating the mitochondrial pathways. Blood 109: 5455-5462, 2007.

34. Spencer JP, Rice-Evans C and Williams RJ: Modulation of pro-survival Akt/protein kinase B and ERK1/2 signaling cascades by quercetin and its in vivo metabolites underlie their action on neuronal viability. J Biol Chem 278: 34783-34793, 2003.

35. Allander T, Forns X, Emerson SU, Purcell RH and Bukh J: Hepatitis $\mathrm{C}$ virus envelope protein E2 binds to CD81 of tamarins. Virology 277: 358-367, 2000

36. Higginbottom A, Quinn ER, Kuo CC, Flint M, Wilson LH, Bianchi E, Nicosia A, Monk PN, McKeating JA and Levy S: Identification of amino acid residues in CD81 critical for interaction with hepatitis $\mathrm{C}$ virus envelope glycoprotein E2. J Virol 74 3642-3649, 2000.

37. Tedder TF, Zhou LJ and Engel P: The CD19/CD21 signal transduction complex of B lymphocytes. Immunol Today 15: 437-442, 1994.

38. Hur DY, Lee MH, Kim JW, Kim JH, Shin YK, Rho JK, Kwack KB, Lee WJ and Han BG: CD19 signalling improves the Epstein-Barr virus-induced immortalization of human B cell. Cell Prolif 38: 35-45, 2005

39. Dolcetti R and Masucci MG: Epstein-Barr virus: induction and control of cell transformation. J Cell Physiol 196: 207-218, 2003
40. Bornkamm GW and Hammerschmidt W: Molecular virology of Epstein-Barr virus. Philos Trans R Soc Lond B Biol Sci 356: 437-459, 2001.

41. Sugawara Y, Mizugaki Y, Uchida T, Torii T, Imai S, Makuuchi M and Takada K: Detection of Epstein-Barr virus (EBV) in hepatocellular carcinoma tissue: a novel EBV latency characterized by the absence of EBV-encoded small RNA expression. Virology 256: 196-202, 1999.

42. Akhter S, Liu H, Prabhu R, DeLucca C, Bastian F, Garry RF, Schwartz M, Thung SN and Dash S: Epstein-Barr virus and human hepatocellular carcinoma. Cancer Lett 192: 49-57, 2003.

43. Welker MW, Hofmann WP, Lange CM, Herrmann E, Sarrazin C, Zeuzem S and Kronenberger B: CD81 expression for discrimination between sustained virologic response and relapse in patients with chronic hepatitis C. Scand J Gastroenterol 46: 973-980, 2011.

44. Hermine O, Lefrère F, Bronowicki JP, Mariette X, Jondeau K, Eclache-Saudreau V, Delmas B, Valensi F, Cacoub P, Brechot C, et al: Regression of splenic lymphoma with villous lymphocytes after treatment of hepatitis C virus infection. N Engl J Med 347: 89-94, 2002.

45. Altomonte M, Montagner R, Pucillo $\mathrm{C}$ and Maio M: Triggering of target of an antiproliferative antibody-1 (TAPA-1/CD81) up-regulates the release of tumour necrosis factor-alpha by the EBV-B lymphoblastoid cell line JY. Scand J Immunol 43: 367-373, 1996.

46. Snow AL, Chen LJ, Nepomuceno RR, Krams SM, Esquivel CO and Martinez OM: Resistance to Fas-mediated apoptosis in EBV-infected B cell lymphomas is due to defects in the proximal Fas signaling pathway. J Immunol 167: 5404-5411, 2001.

47. Tepper CG and Seldin MF: Modulation of caspase- 8 and FLICE-inhibitory protein expression as a potential mechanism of Epstein-Barr virus tumorigenesis in Burkitt's lymphoma. Blood 94: 1727-1737, 1999.

48. Andreyev AY, Kushnareva YE and Starkov AA: Mitochondrial metabolism of reactive oxygen species. Biochemistry (Mosc) 70: 200-214, 2005.

49. Filomeni G, Aquilano K, Rotilio G and Ciriolo MR: Reactive oxygen species-dependent c-Jun NH2-terminal kinase/c-Jun signaling cascade mediates neuroblastoma cell death induced by diallyl disulfide. Cancer Res 63: 5940-5949, 2003.

50. Zignego AL, Macchia D, Monti M, Thiers V, Mazzetti M, Foschi M, Maggi E, Romagnani S, Gentilini P and Bréchot C: Infection of peripheral mononuclear blood cells by hepatitis $\mathrm{C}$ virus. J Hepatol 15: 382-386, 1992.

51. Zuckerman E, Slobodin G, Kessel A, Sabo E, Yeshurun D, Halas K and Toubi E: Peripheral B cell CD5 expansion and CD81 overexpression and their association with disease severity and autoimmune markers in chronic hepatitis $\mathrm{C}$ virus infection. Clin Exp Immunol 128: 353-358, 2002. 